\title{
Improved thermal resistance network model of motorized spindle system considering temperature variation of cooling system
}

\author{
Yang Liu ${ }^{1} \cdot$ Ya-Xin $\mathrm{Ma}^{1} \cdot$ Qing-Yu Meng ${ }^{1} \cdot$ Xi-Cheng Xin ${ }^{1} \cdot$ Shuai-Shuai Ming ${ }^{1}$
}

Received: 11 July 2018/ Accepted: 30 October 2018/Published online: 20 November 2018

(C) The Author(s) 2018

\begin{abstract}
In the motorized spindle system of a computer numerical control (CNC) machine tool, internal heat sources are formed during high-speed rotation; these cause thermal errors and affect the machining accuracy. To address this problem, in this study, a thermal resistance network model of the motorized spindle system is established based on the heat transfer theory. The heat balance equations of the critical thermal nodes are established according to this model with Kirchhoff's law. Then, they are solved using the Newmark- $\beta$ method to obtain the temperature of each main component, and steady thermal analysis and transient thermal analysis of the motorized spindle system are performed. In order to obtain accurate thermal characteristics of the spindle system, the thermalconduction resistance of each component and the thermalconvection resistance between the cooling system and the components of the spindle system are accurately obtained considering the effect of the heat exchanger on the temperature of the coolant in the cooling system. Simultaneously, high-precision magnetic temperature sensors are used to detect the temperature variation of the spindle in the CNC machining center at different rotational speeds. The experimental results demonstrate that the thermal resistance network model can predict the temperature field distribution in the spindle system with reasonable accuracy. In addition, the influences of the rotational speed and cooling conditions on the temperature increase of the main components of the spindle system are analyzed. Finally, a
\end{abstract}

Yang Liu

liuyang1982@mail.neu.edu.cn

1 School of Mechanical Engineering and Automation, Northeastern University, Shenyang 110819, Liaoning, People's Republic of China few recommendations are provided to improve the thermal performance of the spindle system under different operational conditions.

Keywords Motorized spindle system - Thermal resistance network model $\cdot$ Temperature field $\cdot$ Cooling system

\section{Introduction}

In recent years, high-speed machining technology that integrates the advantages of high efficiency, high quality, and low consumption has drawn increasing attention. As a new technology that combines the motor with the spindle of the machine, the motorized spindle has also come into being and become a key part of high-speed machining technology. Moreover, owing to its structural characteristics, the large amount of heat generated by the spindle system at high speed is an important cause of the total thermal error [1]. The thermal deformation during the operation of the spindle system generally results in thermal errors in the machining process of the CNC machine, thus affecting the machining accuracy and hindering the further improvement of machining accuracy. To compensate for the thermal error accurately, one of the urgent problems to be resolved is the accurate prediction of the temperature field distribution of the main components under high-speed operation of the motorized spindle system.

At present, there are mainly two methods for solving the temperature distribution of the spindle system: one is analytical calculation, and the other is numerical analysis including finite element method (FEM) and finite difference method (FDM). For these two methods, domestic and international scholars have conducted numerous meaningful research works. Zhu et al. [2] proposed a two- 
dimensional thermal model of the spindle that considered axial and radial heat transfer. Similarly, Yang and Ni [3] used the simulation of one-dimensional spindle and twodimensional machine structure thermal deformations to illustrate the modeling process. Jiang et al. [4] studied the variation of the heat dynamic characteristics of one-dimensional spindle. Xie et al. [5] proposed an improved one-dimensional model and derived the temperature distribution function of the spindle system based on the transient heat transfer equation and boundary conditions. With the rapid development of computer science, certain commercial computing softwares such as ANSYS and ABAQUS are also applied for analyzing the thermal characteristics of the spindle [6-10]. Based on the quasistatic model and FDM, Than and Huang [11] proposed a unified method for predicting the nonlinear thermal characteristics of high-speed spindle bearings. Bossmanns and $\mathrm{Tu}[12,13]$ proposed a power flow model and established a thermal analysis model of the high-speed spindle using FEM. Zverev et al. [14] established a model of heat generation and heat transfer using FEM, for estimating spindle temperature. The temperature field of the spindle system can also be obtained by the thermal resistance network method. Huang et al. [15] and Liu et al. [16] used thermal nodes to represent different components in the shaft system and obtained the temperature distribution of the system by solving the heat balance equations. Liu et al. [17] established the thermal resistance network model of a spindlebearing pedestal based on fractal and the Hertz contact theory. Wu and Tan [18] studied a mathematical model of the temperature field of a spindle according to the theory of heat transfer and analyzed the influence of the cooling system on the temperature distribution. Xu et al. [19] and Ma et al. [20, 21] proposed applying a finite element analysis model to analyze the temperature field of the spindle system. The thermal resistance model and FEM were combined to obtain the calculation model of the large gradient temperature field.

According to the above literature, there has been a large amount of research on the thermal characteristic of motorized spindle system in the past. However, few studies consider the cooling condition to a significant extent. Nevertheless, practically, the temperature of the coolant is significantly influenced by the heat exchanger. Based on the models established by the predecessors, the motorized spindle system of CNC machining center is considered as the research object in this study. Based on Kirchhoff's law and the principle of conservation of energy, the improved thermal resistance network model of the system is established, and the steady and transient temperature characteristics of the motorized spindle system are obtained by the Newmark- $\beta$ method. The influence of the radial and axial thermal-conduction resistance and thermal- convection resistance between the cooling system and the components of the spindle system on the temperature rise is considered in this model. Furthermore, in order to improve the accuracy and practicality of the calculation results of this model, the influence of the heat exchanger on the temperature variation of the coolant is also considered. In addition, the temperature increase experiments of the motorized spindle at different speeds, in conjunction with the above experiments, verified that this model could accurately predict the temperature distribution and transient temperature variation of the system. Certain important factors that affect the temperature variation of the system are also analyzed to compensate and correct the thermal error under different operating conditions more reasonably.

\section{Thermal resistance network model of motorized spindle system}

\subsection{Structure and heat transfer mechanism of the system}

As the core component of high-end CNC machine tools, the motorized spindle system includes the shaft, bearings, motor, and rack as the four main components; of these, the spindle-bearing system is the most critical. To a considerable extent, the size parameters and fit condition of the spindle-bearing system exert a significant impact on the cutting speed and machining accuracy of the spindle system. The structure diagram of the motorized spindle system investigated in this study is shown in Fig. 1. It comprises the front bearings, lubrication circuit, rotor and stator of the built-in motor, cooling slot, rear bearing, shell and flange cover, etc. Two sets of "face-to-face" angular contact bearings are used at the front of the motorized spindle system, and a cylindrical roller bearing is used as an auxiliary support at the rear of the system. The motor stator is cooled by an oil-water circulation heat-exchange system.

The heat generation in the motorized spindle system of high-end CNC machine tools is generally non-constant and complex. In the machining process, the heat sources that affect the machining accuracy of the machine tools can be divided into two major categories: internal heat sources and external heat sources [22, 23]. For the center-mounted motorized spindle system in this study, the internal heat sources are mainly the motor and bearings. The external heat sources are mainly external environmental factors or heat radiation. In this study, the external temperature is set to room temperature, and the temperature difference, sunlight, lighting, etc., are excluded.

In addition to considering the heat sources of the spindle system, the cooling mechanism should be considered. 


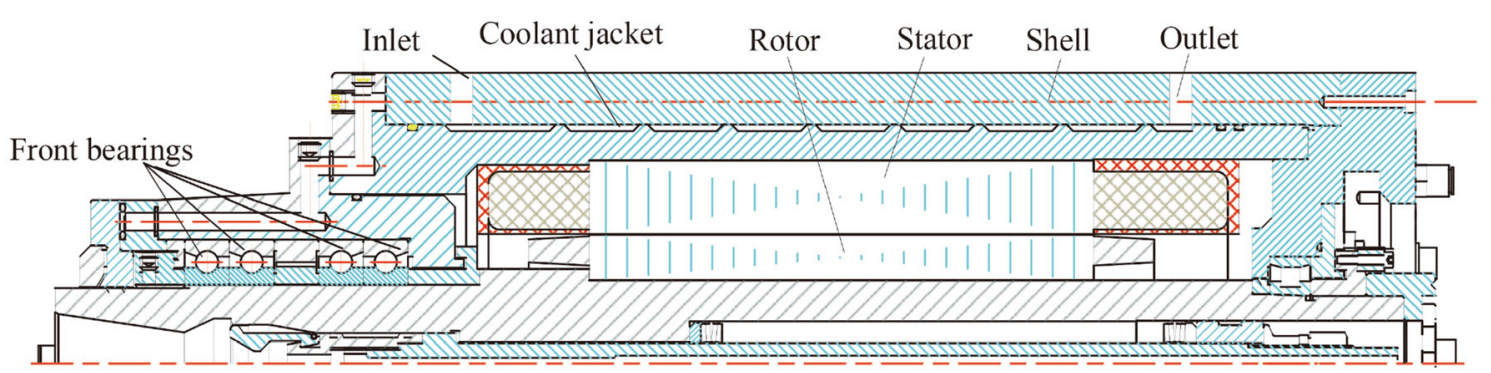

Fig. 1 Structure of the motorized spindle

According to the theory of heat transfer, there are three fundamental modes of heat transfer: conduction heat transfer, convection heat transfer, and radiative heat transfer. Because the effect of heat radiation in the heat dissipation process is marginal, this paper mainly discusses the first two modes. The heat dissipation mechanism of the spindle system is shown in Fig. 2. There are two main heat dissipation modes of the spindle system: the heat generated by the built-in motor is absorbed and carried away by the coolant of the oil-water heat exchange cooling system; the heat generated by the bearings is absorbed by the lubricating fluid in the oil-air lubrication system. Moreover, the heat convection between the spindle system and the ambient air is included.

\subsection{Establishment of the thermal resistance network model}

Based on the above structure of the motorized spindle system, a thermal network model of the main components of the spindle system is established by using the thermal resistance network method. The thermal resistance network method is a numerical method with thermoelectric analogy, which can address complex heat-transfer problems. Therefore, considering the thermal-conductive resistance and thermal-convection resistance, a thermal resistance network model of the spindle system is established. Simultaneously, the heat balance equation of each thermal node is established according to the law of conservation of energy to obtain the temperature of each thermal node. The

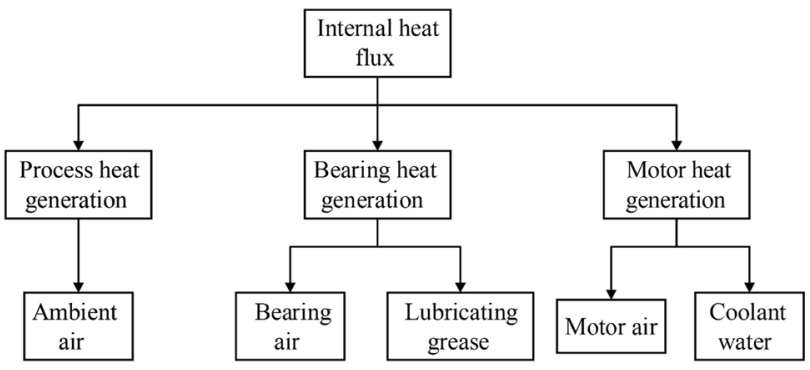

Fig. 2 Heat dissipation mechanism of the spindle system distribution position diagram of the thermal node of the spindle system is shown in Fig. 3 .

Based on the distribution of the thermal nodes in Fig. 3 and the heat transfer and dissipation mechanism of the motorized spindle system, the thermal resistance network model of the whole system can be obtained, as shown in Fig. 4, which shows that there are 32 thermal nodes including the coolant and ambient. Further details are listed in Table 1. In addition, the thermal resistance between the nodes, including the thermal-conduction resistance and thermal-convection resistance, is also shown in Fig. 4.

\subsection{Establishment and solution of heat balance equations}

It is assumed that each of the thermal nodes is linked to the others through thermal resistance $R_{i, j}$, where $i$ and $j$ are the indices of the linked nodes. Then, according to Kirchhoff's law and the law of conservation of energy, for each node $i$ in Fig. 4, the following heat balance equation is established

$\sum_{j=1}^{n} \frac{t_{j}-t_{i}}{R_{i, j}}+\dot{Q}_{i}=m_{i} C_{i} \frac{\partial t_{i}}{\partial \tau}, \quad i=1,2, \cdots, n$,

where $t_{i}$ the temperature of node $i, m_{i}$ the mass of node $i, C_{i}$ the specific heat capacity, $R_{i, j}$ the resistance between nodes $i$ and $j$, and $\dot{Q}_{i}$ the heat generated per unit time for node $i$ (If there is no internal heat source, this term should be omitted). Moreover, $n=32$ in this model. Then, the matrix form arranged based on the above heat balance equations is as follows

$R \boldsymbol{T}+\boldsymbol{C} \dot{\boldsymbol{T}}=\boldsymbol{Q}$,

where $\boldsymbol{R}$ the thermal resistance coefficient matrix, $\boldsymbol{C}$ the heat capacity matrix, $\boldsymbol{Q}$ the heat flow matrix, and $\boldsymbol{T}$ the node temperature matrix. The specific expressions of each matrix are as follows 


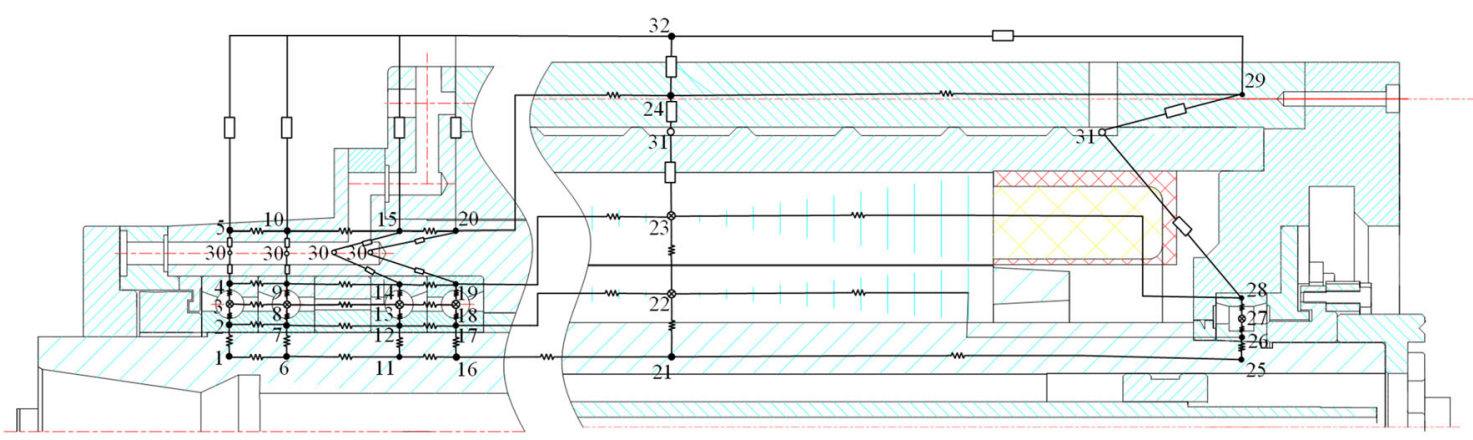

Fig. 3 Diagrammatic sketch of heat nodes distribution

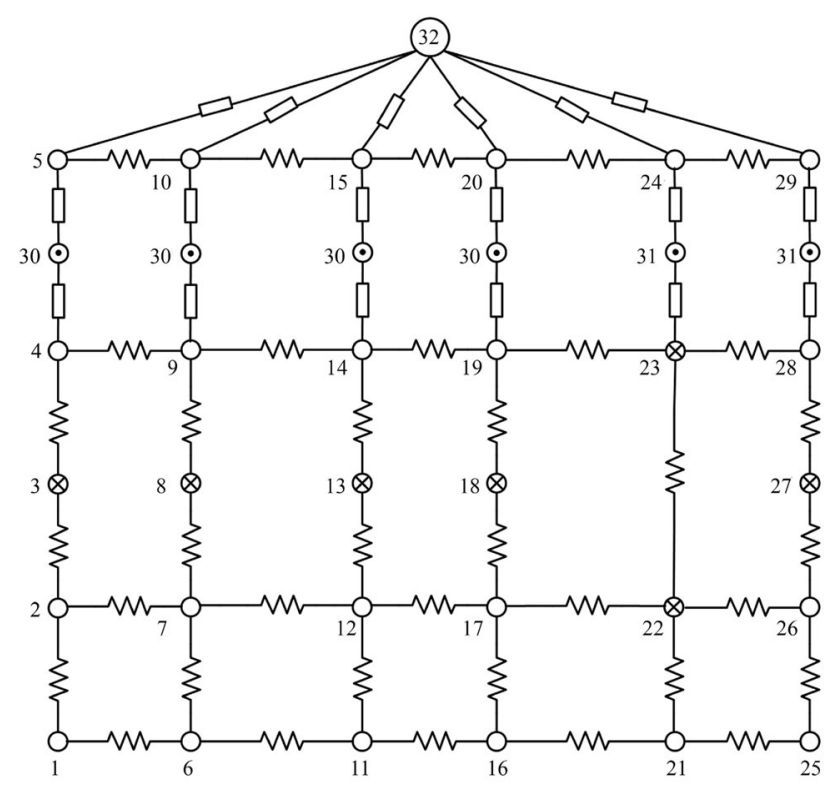

$$
\begin{aligned}
& \text { Thermal node } \\
& \otimes \text { Heat source } \\
& \odot \text { Lubricating liquid }
\end{aligned}
$$

Fig. 4 Thermal resistance network model

$$
\boldsymbol{R}=\left[\begin{array}{lllll}
\sum_{i=1}^{n} \frac{1}{R_{1, i}} & \frac{-1}{R_{1,2}} & \frac{-1}{R_{1,3}} & \cdots & \frac{-1}{R_{1, n}} \\
\frac{-1}{R_{2,1}} & \sum_{i=1}^{n} \frac{1}{R_{2, i}} & \frac{-1}{R_{2,3}} & \cdots & \frac{-1}{R_{2, n}} \\
\frac{-1}{R_{3,1}} & \frac{-1}{R_{3,2}} & \sum_{i=1}^{n} \frac{1}{R_{3, i}} & \cdots & \frac{-1}{R_{3, n}} \\
\vdots & \vdots & \vdots & \ddots & \vdots \\
\frac{-1}{R_{n, 1}} & \frac{-1}{R_{n, 2}} & \frac{-1}{R_{n, 3}} & \cdots & \sum_{i=1}^{n} \frac{1}{R_{n, i}}
\end{array}\right],
$$

Table 1 Description on nodes arrangement

\begin{tabular}{ll}
\hline Node & Description \\
\hline $1,6,11,16,21,25$ & Different positions on the shaft \\
$2,7,12,17$ & Inner ring of the front bearings \\
26 & Inner ring of rear bearing \\
$3,8,13,18$ & Roller of front bearings \\
27 & Roller of rear bearing \\
$4,9,14,19$ & Outer ring of the front bearings \\
28 & Outer ring of the rear bearing \\
22,23 & Rotor and stator \\
$5,10,15,20$ & Different positions of front bearing chamber \\
24 & Shell \\
29 & Rear bearing chamber \\
30 & Coolant of bearing cooling system \\
31 & Coolant of stator cooling system \\
32 & Ambient air \\
\hline
\end{tabular}

When solving Eq (2), the thermal resistance $R_{i, j}$ is considered to be infinite if there is no heat transfer between nodes $i$ and $j . T_{32}$ represents the ambient air, and $T_{32}=23{ }^{\circ} \mathrm{C}$. Furthermore, the temperature of the coolant $T_{30}$ and $T_{31}$ simulate the temperature variation during the actual operational process. That is, the heat exchanger is set to start operating when the coolant outlet temperature attains $22{ }^{\circ} \mathrm{C}$ and stops working when the coolant is cooled to $19^{\circ} \mathrm{C}$. Then, the temperature curve is obtained by using the orthogonal least square method, as shown in Fig. 5.

The temperature curve of each node can be obtained by solving the above heat balance equations using the 


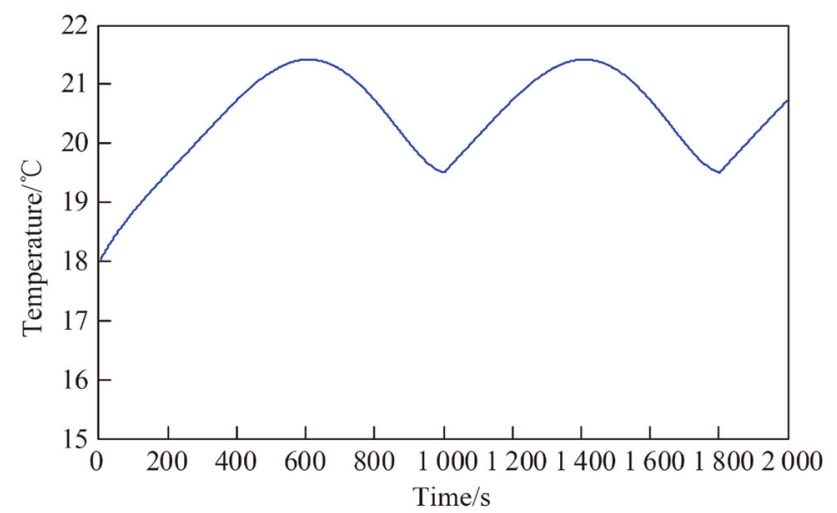

Fig. 5 Coolant temperature curve

Newmark- $\beta$ method. Then, the temperature variation and other thermal characteristics of each component of the motorized spindle system can be analyzed. The calculation of the other parameters involved in the equations is described in the following sections.

\section{Calculation of heat generation and thermal resistance}

\subsection{Heat generation of the heat sources}

The internal heat sources of the motorized spindle system are the build-in motor and bearings. Approximately one third of the motor's heat generation is generated by the motor rotor, and the remaining two-third is generated by the motor's stator. The bearings B7014-C-T-P4S and N1012-K-M1-SP are selected for the front and rear bearings, respectively. The bearing parameters are presented in Table 2.

According to experience and related research, the main factor influencing bearing heat generation is the friction of the high-speed ball bearings. Therefore, the main factors affecting the heat generation of the bearing are the rotational speed and friction moment. The method of calculating the heat generation of the bearing in unit time is illustrated by

$Q=1.047 \times 10^{-4} n M$,

where $n$ is the rotational speed and $M$ is the total friction torque of the bearing.
Based on the measurement results of the friction torque of the bearing, Palmgren [24] proposed the total friction torque of the bearing comprises two items, as explained by $M=M_{\mathrm{s}}+M_{1}$,

where $M_{\mathrm{s}}$ is the torque related to the type of bearing, the speed, and the properties of the lubricating oil, $M_{1}$ the friction torque related to the load on the bearing. $M_{\mathrm{s}}$ reflects the hydrodynamic loss of the lubricant, and it can be calculated by

$M_{\mathrm{s}}= \begin{cases}10^{-7} f_{0}(v n)^{2 / 3} D_{\mathrm{m}}^{3}, & v n>2000, \\ 1.6 \times 10^{-5} f_{0} D_{\mathrm{m}}^{3}, & v n \leq 2000,\end{cases}$

where $D_{\mathrm{m}}$ is the average diameter of the bearing, $f_{0}$ the factor related to the type of bearing and the lubrication mode, and $v$ the kinematic viscosity of the lubricant at the operating temperature.

$M_{1}$ reflects the friction loss of the elastic hysteresis and the local differential sliding, which can be calculated by

$$
\begin{aligned}
& M_{1}=f_{1} P_{1} D_{\mathrm{m}}, \\
& P_{1}=\max \left(0.9 F_{\mathrm{a}} / \tan \alpha-0.1 F_{\mathrm{r}}, F_{\mathrm{r}}\right),
\end{aligned}
$$

where $f_{1}$ a factor related to the type of bearing and the load, and it can be obtained from Ref. [25]. $P_{1}$ is the equivalent load applied on the bearings, and $F_{\mathrm{a}}$ and $F_{\mathrm{r}}$ denote the bearing's axial and radial loads, respectively.

Figures 6 and 7 are the variation curves of the friction torque and the heat generation rate of the bearings, respectively, with respect to the rotational speed. It is evident that the rotational speed exerts a highly significant effect on the heat generation rate of the bearing. As the friction torque of the bearing increases with the increase in the rotational speed, the heat generation rate of the bearing under the high-speed condition is higher than that under the low-speed condition. Table 3 presents the heat generation rate of the main heat source of the motorized spindle system at $10000 \mathrm{r} / \mathrm{min}$.

\subsection{Calculation of thermal resistance}

Heat transfer, a transfer process in nature, is similar to other transfer processes in nature, such as electricity transfer, momentum transfer and mass transfer. The common regularity of the various transfer processes can be expressed in the following form [26]

Table 2 Bearing parameters

\begin{tabular}{llccc}
\hline & Inner diameter/mm & Outer diameter/mm & Thickness $/ \mathrm{mm}$ & Contact angle $/\left({ }^{\circ}\right)$ \\
\hline Front bearing & 70 & 110 & 20 & 15 \\
Rear bearing & 60 & 95 & 18 & 15 \\
\hline
\end{tabular}




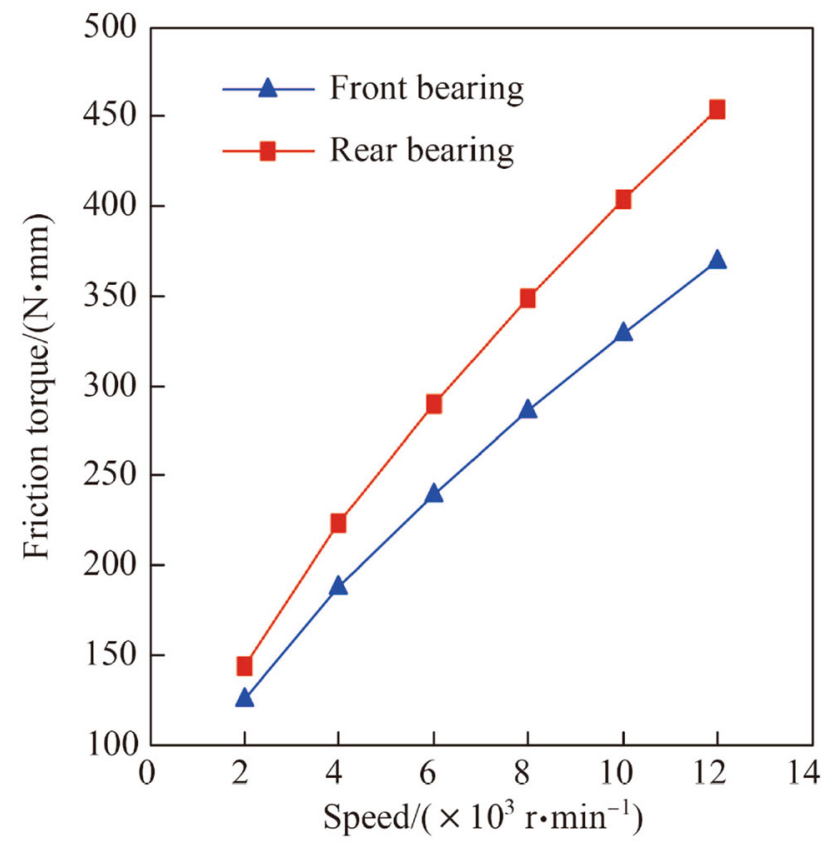

Fig. 6 Friction torque of front and rear bearings versus rotational speed

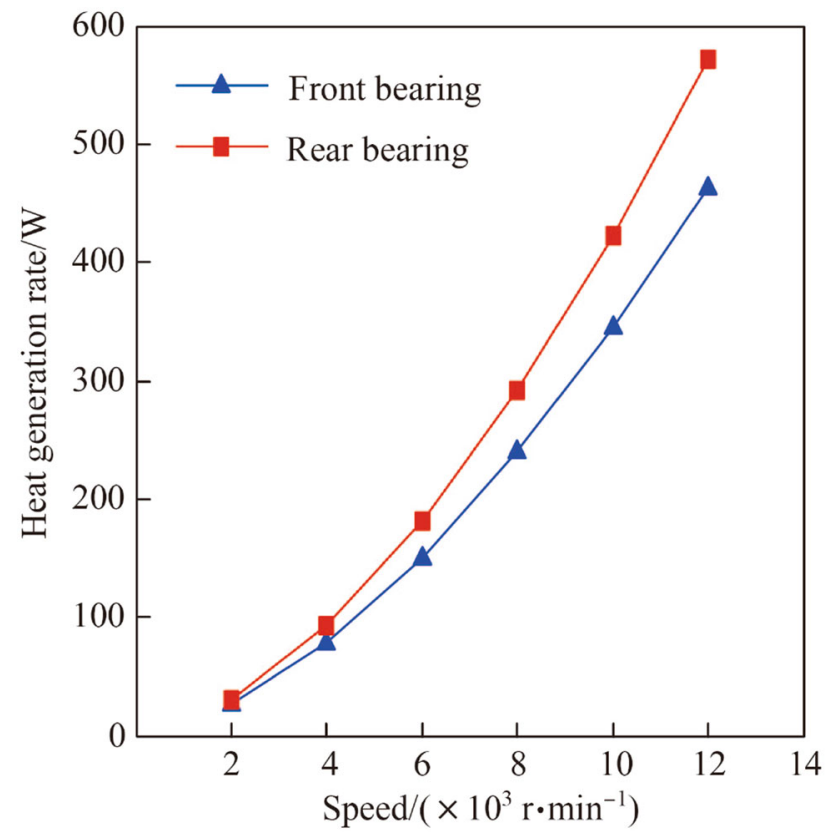

Fig. 7 Heat generation rate of the front and rear bearings versus rotational speed

Table 3 Heat generation of heat sources

\begin{tabular}{lllll}
\hline & Rotor & Stator & Front bearing & Rear bearing \\
\hline Heat generation/W & 183.3 & 366.7 & 368.7 & 454.4 \\
\hline
\end{tabular}

The amount of transfer in the process

$$
=\frac{\text { The power in the process }}{\text { The resistance in the process }}
$$

\subsubsection{Thermal contact resistance}

Owing to the mutual cooperation between the various components in the motorized spindle system, a plurality of the different bonding surfaces are formed, such as the joint between the inner ring of the bearing and the shaft, and the outer ring of the bearing and the bearing pedestal. Moreover, the heat transfer characteristics directly influence the heat transfer of the heat source and the temperature change of the system. Therefore, the influence of the heat transfer characteristics of these joints on the temperature field of the system cannot be omitted. The joint surfaces involved in this system are all formed by the contact of two solid surfaces that are uneven. Furthermore, the void is filled with a medium with low thermal conductivity (such as air), and the actual contact area is small. Therefore, the heat transfer in the contact surface produces resistance, i.e., thermal contact resistance.

(i) The Hertz contact theory is used for calculating the thermal contact resistance between the rolling elements and the bearing rings in the system. The thermal contact resistance per rolling element can be expressed as follows

$$
\begin{aligned}
R & =\frac{1}{2 k F^{1 / 3}}\left(\frac{\frac{2}{\pi} K_{1}\left(e_{\mathrm{i}}, \pi / 2\right)}{\left(\frac{3 D_{\mathrm{i}}}{4}(I+J)\right)^{1 / 3}}+\frac{\frac{2}{\pi} K_{1}\left(e_{\mathrm{o}}, \pi / 2\right)}{\left(\frac{3 D_{\mathrm{o}}}{4}(I+J)\right)^{1 / 3}}\right) \\
& \cong \frac{1}{\pi k}\left(\frac{K_{1}\left(e_{\mathrm{i}}, \pi / 2\right)}{a_{\mathrm{i}}}+\frac{K_{1}\left(e_{\mathrm{o}}, \pi / 2\right)}{a_{\mathrm{o}}}\right),
\end{aligned}
$$

where $k$ is the thermal conductivity of the bearing material, $F$ the contact force, $K_{1}$ the first type of complete elliptic integral, $e$ eccentricity of ellipse, $a$ elliptic semi-major, and $\mathrm{i}$ and o represent inner and outer rings respectively. $D$ is diameter of raceway, $\quad D_{\mathrm{i}}=\frac{2}{A_{\mathrm{i}}+B_{\mathrm{i}}}\left(\frac{1-v^{2}}{\pi E}\right), \quad D_{\mathrm{o}}=\frac{2}{A_{\mathrm{o}}+B_{\mathrm{o}}}\left(\frac{1-v^{2}}{\pi E}\right)$, where $E$ and $v$ are elastic modulus and poisson ratio respectively, and $A$ and $B$ are the parameters related to the curvature radius. For the contact between the bearing roller and the inner ring,

$$
\left\{\begin{aligned}
A_{\mathrm{i}}+B_{\mathrm{i}} & =\frac{1}{2}\left(-\frac{1}{r_{\mathrm{i}}^{\prime}}+\frac{1}{r_{\mathrm{i}}}+\frac{2}{r_{\mathrm{b}}}\right), \\
\frac{A_{\mathrm{i}}}{B_{\mathrm{i}}} & =\frac{1 / r_{\mathrm{i}}+1 / r_{\mathrm{b}}}{-1 / r_{\mathrm{i}}^{\prime}+1 / r_{\mathrm{b}}} .
\end{aligned}\right.
$$

For the contact between the bearing roller and the outer ring, 


$$
\left\{\begin{aligned}
A_{\mathrm{o}}+B_{\mathrm{o}} & =\frac{1}{2}\left(-\frac{1}{r_{\mathrm{o}}^{\prime}}-\frac{1}{r_{\mathrm{o}}}+\frac{2}{r_{\mathrm{b}}}\right), \\
\frac{A_{\mathrm{o}}}{B_{\mathrm{o}}} & =\frac{-1 / r_{\mathrm{o}}+1 / r_{\mathrm{b}}}{-1 / r_{\mathrm{o}}^{\prime}+1 / r_{\mathrm{b}}},
\end{aligned}\right.
$$

where $\mathrm{b}$ represent the rolling element, inner ring, and outer ring, respectively. $r$ and $r^{\prime}$ are the radii of curvature of the raceway and groove, respectively. For the bearing inner ring and rolling element contact, $r_{\mathrm{i}}^{\prime}>0, r_{\mathrm{i}}>0, r_{\mathrm{b}}>0$. For the bearing outer ring and rolling element contact, $r_{\mathrm{o}}^{\prime}<0, r_{\mathrm{o}}>0, r_{\mathrm{b}}>0$.

Furthermore,

$$
\left\{\begin{array}{l}
e=\left(1-(b / a)^{2}\right)^{1 / 2} \\
I=2 / e^{2}\left(K_{1}(e, \pi / 2)-K_{2}(e, \pi / 2)\right), \\
J=\frac{2}{e^{2}}\left(\frac{K_{2}(e, \pi / 2)}{1-e^{2}}-K_{1}(e, \pi / 2)\right),
\end{array}\right.
$$

where $\delta$ is the average thickness of the voids. $\lambda_{1}, \lambda_{2}$, and $\lambda_{3}$ are the thermal conductivity of the two objects and the medium, respectively. $S$ is the total area of the nominal contact.

(iii) The thermal contact resistance between the bearing outer ring and the pedestal in the system is a function of the air gap related to the temperature. It can be calculated by the following formula

$R=\frac{h_{\mathrm{r}}}{\lambda_{\mathrm{r}} A}+\frac{h_{\mathrm{g}}-\left(T_{\mathrm{r}}-T_{\mathrm{h}}\right) \alpha r_{\mathrm{p}}}{\lambda_{\mathrm{a}} A}$,

where $\lambda_{\mathrm{r}}$ and $\lambda_{\mathrm{a}}$ are the coefficients of the bearing outer ring and medium, respectively; $A$ is the cylindrical outer surface area of the bearing outer ring; $h_{\mathrm{r}}, h_{\mathrm{g}}$ are the bearing ring's thickness and initial clearance, respectively; $T_{\mathrm{r}}, T_{\mathrm{p}}$ are the temperatures of the outer ring and bearing pedestal, respectively; $\alpha$ is the linear expansion coefficient; $r_{\mathrm{p}}$ is the bearing pedestal radius.

$$
\left\{\begin{aligned}
& K_{1}(e, \pi / 2)=\int_{0}^{\pi / 2} \frac{d \xi}{\left(1-e^{2} \sin ^{2} \xi\right)^{1 / 2}} \\
&= \frac{\pi}{2}\left(1+\left(\frac{1}{2}\right)^{2} e^{2}+\left(\frac{1 \cdot 3}{2 \cdot 4}\right)^{2} e^{4}+\cdots+\left(\frac{(2 n-1)(2 n-3) \cdots 3 \cdot 1}{2 n(2 n-2) \cdots 4 \cdot 2}\right)^{2} e^{2 n}\right), \\
& K_{2}(e, \pi / 2)=\int_{0}^{\pi / 2}\left(1-e^{2} \sin ^{2} \xi\right)^{1 / 2} d \xi \\
&=\frac{\pi}{2}\left(1-\left(\frac{1}{2}\right)^{2} e^{2}-\left(\frac{1 \cdot 3}{2 \cdot 4}\right)^{2} e^{4}-\cdots-\left(\frac{(2 n-1)(2 n-3) \cdots 3 \cdot 1}{2 n(2 n-2) \cdots 4 \cdot 2}\right)^{2} \frac{e^{2 n}}{2 n-1}\right) .
\end{aligned}\right.
$$

(ii) The approximate formulas for calculating the thermal contact resistance between the bearing inner ring and the shaft and that between the rotor and the mandrel in the system (referring to the Ref. [27]) are as follows

$\frac{1}{R}=\frac{1}{R_{\mathrm{s}}}+\frac{1}{R_{\mathrm{f}}}$,

where $R_{\mathrm{S}}$ is the heat transfer resistance between the solid contact points. $R_{\mathrm{f}}$ is the heat transfer resistance of the medium between the contact points.

If the effective contact area of the joint surface is $S_{\mathrm{c}}$ and the average surface area filled by the intermediate medium is $S_{\mathrm{f}}$,

$R=\frac{1}{\frac{1}{\delta}\left(\frac{S_{\mathrm{c}}}{S} \frac{2 \lambda_{1} \lambda_{2}}{\lambda_{1}+\lambda_{2}}+\frac{S_{\mathrm{f}}}{S} \lambda_{\mathrm{f}}\right)}$,

\subsubsection{Thermal-conduction resistance}

The thermal-conduction resistance of the spindle system is divided into the radial and axial thermal resistances. For the radial thermal resistance of the system, the thermal conduction of the single cylinder wall is considered, as shown in Fig. 8. The inner and outer radii of the cylinder wall are $r_{\mathrm{i}}$ and $r_{\mathrm{o}}$, respectively. The temperatures of the internal and external surfaces are $t_{\mathrm{i}}$ and $t_{\mathrm{o}}$, respectively. Using cylindrical coordinates, this problem becomes a onedimensional heat conduction problem along the radial direction. The heat transfer coefficient $\lambda$ of the material is assumed to be constant. Moreover, the differential equation of heat conduction is expressed

$\frac{\mathrm{d}}{\mathrm{d} r}\left(r \frac{\mathrm{d} t}{\mathrm{~d} r}\right)=0$,

and the corresponding boundary conditions are as follows 


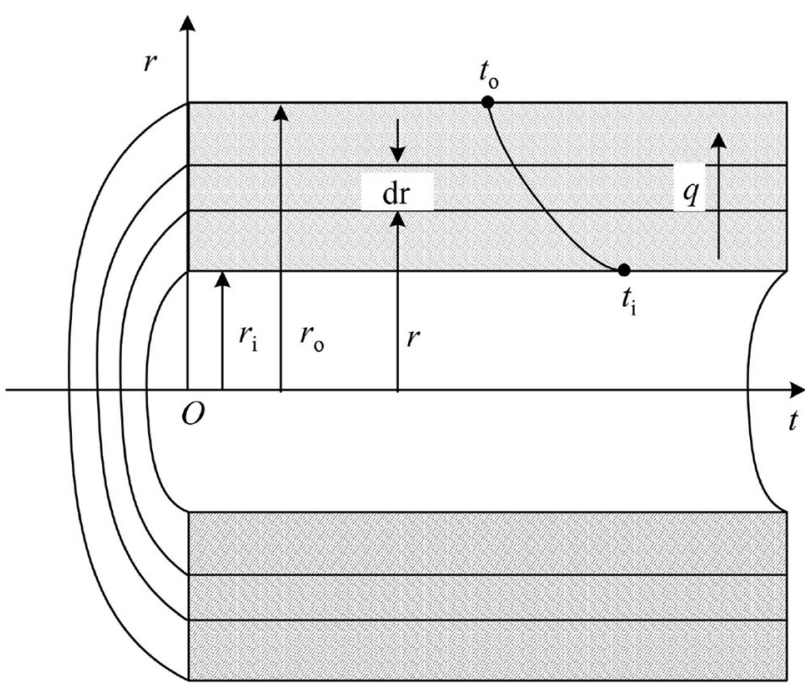

Fig. 8 Schematic diagram of radial heat conduction

$$
\begin{aligned}
& r=r_{\mathrm{i}}, t=t_{\mathrm{i}} \\
& r=r_{\mathrm{o}}, t=t_{\mathrm{o}}
\end{aligned}
$$

Thus, the radial temperature distribution is obtained as $t=t_{\mathrm{i}}+\frac{t_{\mathrm{o}}-t_{\mathrm{i}}}{\ln \left(r_{\mathrm{o}} / r_{\mathrm{i}}\right)} \ln \left(r / r_{\mathrm{i}}\right)$.

It is apparent that the radial temperature distribution in the cylinder wall is a logarithmic curve. Furthermore, according to Fourier's law, the heat flux through the cylinder wall can be obtained after determining the derivative of the above formula, as expressed by

$q=-\lambda \frac{\mathrm{d} t}{\mathrm{~d} r}=\frac{\lambda}{r} \frac{\left(t_{\mathrm{i}}-t_{\mathrm{o}}\right)}{\ln \left(r_{\mathrm{o}} / r_{\mathrm{i}}\right)}$.

Then, the heat flow through the entire cylinder wall is expressed as

$\varphi=2 \pi l r q=\frac{2 \pi \lambda l\left(t_{\mathrm{i}}-t_{\mathrm{o}}\right)}{\ln \left(r_{\mathrm{o}} / r_{\mathrm{i}}\right)}$.

According to the definition of thermal resistance, the thermal-conductive resistance through the entire cylindrical wall can be obtained, which is

$R=\frac{\Delta t}{\varphi}=\frac{\ln \left(d_{\mathrm{o}} / d_{\mathrm{i}}\right)}{2 \pi \lambda l}$,

where $d_{\mathrm{o}}$ is the outer diameter, $d_{\mathrm{i}}$ the inner diameter, and $l$ the width.

The determination of the axial thermal-conduction resistance is also considered as a one-dimensional heat conduction problem; its calculation method is similar to that of the radial thermal resistance. Figure 9 shows the schematic diagram. The conduction differential equation is expressed by

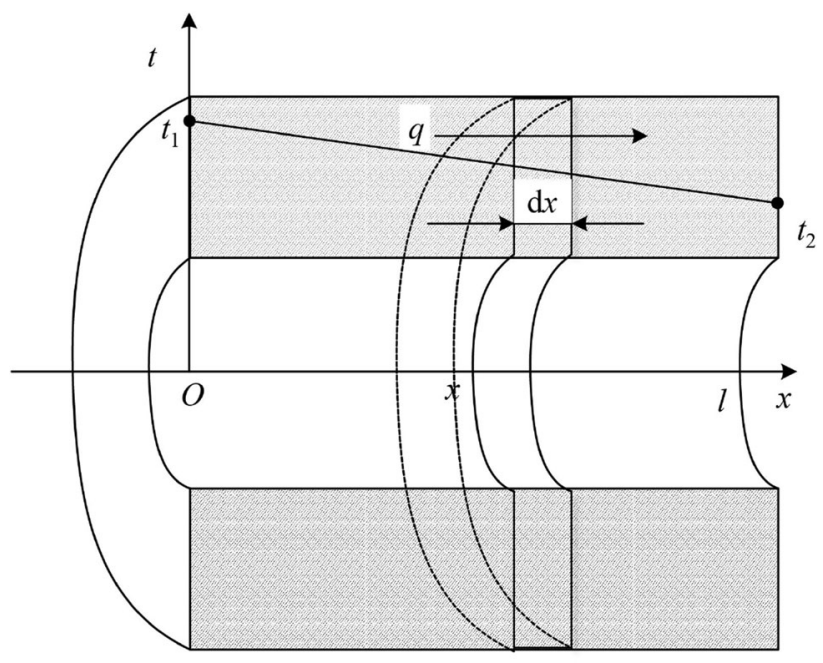

Fig. 9 Schematic diagram of axial heat conduction

$\frac{\mathrm{d}^{2} t}{\mathrm{~d} x^{2}}=0$

and the corresponding boundary conditions are as follows $x=0, t=t_{1}$,

$x=l, t=t_{2}$,

The axial temperature distribution is obtained according to the above formula, as expressed by

$t=\frac{t_{2}-t_{1}}{l} x+t_{1}$.

According to Fourier's law, the expression for heat flow can be obtained as

$\varphi=\frac{\lambda S\left(t_{2}-t_{1}\right)}{l}$.

The axial thermal-conduction resistance in the system can be calculated by

$R=\frac{\Delta t}{\varphi}=\frac{l}{\lambda S}=\frac{4 l}{\pi \lambda\left(d_{2}^{2}-d_{1}^{2}\right)}$.

\subsubsection{Thermal-convection resistance}

According to the causes of flow, the convective heat transfer can be divided into natural convection and forced convection. In this study, the heat transfer in the oil-water cooling system at the stator of the motorized spindle system and that in the oil-gas lubrication cooling system at the bearing belong to the latter category. The fundamental formula for convective heat transfer is Newton's law of cooling, which is as follows 
$q=h \Delta t$,

$\varphi=h A \Delta t$,

where $\Delta t$ is the difference between the temperature of the wall and that of the fluid, which is always set to be positive. $h$ is the convection heat-transfer coefficient, and $A$ is the surface area of heat transfer. The thermal-convective resistance can be calculated by

$R=\frac{\Delta t}{\varphi}=\frac{1}{h A}=\frac{4 l}{\pi h d^{2}}$,

The convection heat-transfer coefficient $h$ changes with the cooling conditions. The three cooling conditions in this motorized spindle system are as follows: convection heat transfer between the system and the surrounding air, convection heat transfer between the end of rotor and the surrounding air, and convection heat transfer between the stator and the coolant in the cooling water jacket. The heat transfer coefficients for the above three cases are calculated as follows.

Both convective as well as radiative heat transfer occur between the spindle system and the ambient air. This type of heat transfer wherein radiation and convection occur simultaneously is called compound heat transfer. Because this situation is complicated and the radiative heat transfer plays a minor role in heat dissipation, the radiation is directly translated into heat convection in this study. When the initial temperature of the ambient air is $20{ }^{\circ} \mathrm{C}$, the surface heat-transfer coefficient of the shaft and the ambient air can be calculated by the Nusselt equation, which is expressed as

$\frac{h x}{\lambda}=0.332\left(\frac{u_{\infty} x}{v}\right)^{\frac{1}{2}}\left(\frac{v}{\alpha}\right)^{\frac{1}{3}}$,

$h=0.332 \frac{\lambda}{x}\left(\frac{u_{\infty} x}{v}\right)^{\frac{1}{2}}\left(\frac{v}{\alpha}\right)^{\frac{1}{3}}=0.332 \frac{\lambda}{x} \operatorname{Rex}^{\frac{1}{2}} \operatorname{Pr}^{\frac{1}{3}}$,

where $u_{\infty}$ the velocity of the fluid, $\lambda$ the thermal conductivity of the fluid, $\alpha$ the thermal diffusivity, $v$ the kinematic viscosity, $\operatorname{Re}$ the Reynolds number, $\operatorname{Pr}$ the Prandtl number, and $x$ the equivalent diameter.

A part of the heat generated by the high-speed rotation of the rotor is transferred to the stator through the air gap; part of it is directly transferred to the shaft and bearings; part of it is transferred to the ambient air through the end. The heat transfer coefficient of convection heat transfer between the rotor end and the ambient air can be calculated by Eq. (32). Furthermore, Fig. 10 is the variation curve that changes with the speed.

$h_{\mathrm{r}}=28\left(1+\sqrt{0.45 \frac{\pi n d}{60}}\right)$.

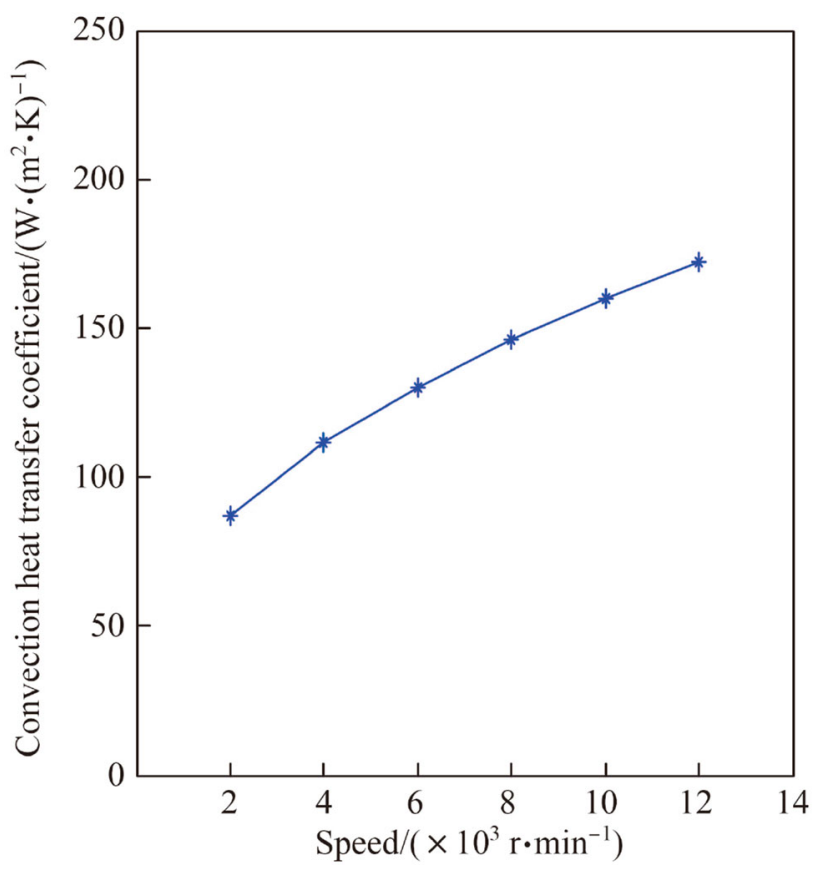

Fig. 10 Heat transfer coefficient $h_{\mathrm{r}}$ versus the rotational speed

For the flow problem of the oil-water heat exchange cooling system of the stator, the flow of the coolant in the cooling tank is limited by the internal surface [28]. First, the concept of mean temperature $t_{\mathrm{m}}$ should be introduced for calculating such a heat transfer coefficient

$t_{\mathrm{m}}=\frac{\int_{\mathrm{A}_{\mathrm{c}}} \rho u c_{\mathrm{p}} t \mathrm{~d} A_{\mathrm{c}}}{\dot{m} c_{\mathrm{p}}}=\frac{2}{u_{\mathrm{m}} r_{\mathrm{o}}^{2}} \int_{0}^{r_{\mathrm{o}}} u t r \mathrm{~d} r$,

where $A_{\mathrm{c}}$ is the cross-sectional area of the coolant tank, $\rho$ density, $c_{\mathrm{p}}$ heat capacity at constant pressure, and $u$ the mass average fluid velocity. Then, Newton's law of cooling can be expressed as

$q=h\left(t_{\mathrm{s}}-t_{\mathrm{m}}\right)$.

An energy balance is applied to determine the variation of the mean temperature $t_{\mathrm{m}}$ with the position along the tube and the relation between the total convection heat transfer $q_{\text {conv }}$ and the difference in the temperatures at the tube inlet and outlet. The fluid flows at a constant flow rate $\dot{m}$, and convection heat transfer occurs at the inner surface. According to the first law of thermodynamics, the energy balance is as follows

$q_{\mathrm{conv}}=\dot{m} c_{\mathrm{p}}\left(t_{\mathrm{m}, \mathrm{o}}-t_{\mathrm{m}, \mathrm{i}}\right)$

where $\mathrm{i}$ and $\mathrm{o}$ are the indices of the inlet and outlet, respectively. For the differential control volume of Fig. 11,

$\frac{\mathrm{d} t_{\mathrm{m}}}{\mathrm{d} x}=\frac{q_{\mathrm{s}}^{\prime \prime} P}{\dot{m} c_{\mathrm{p}}}=\frac{P}{\dot{m} c_{\mathrm{p}}} h\left(t_{\mathrm{s}}-t_{\mathrm{m}}\right)$. 


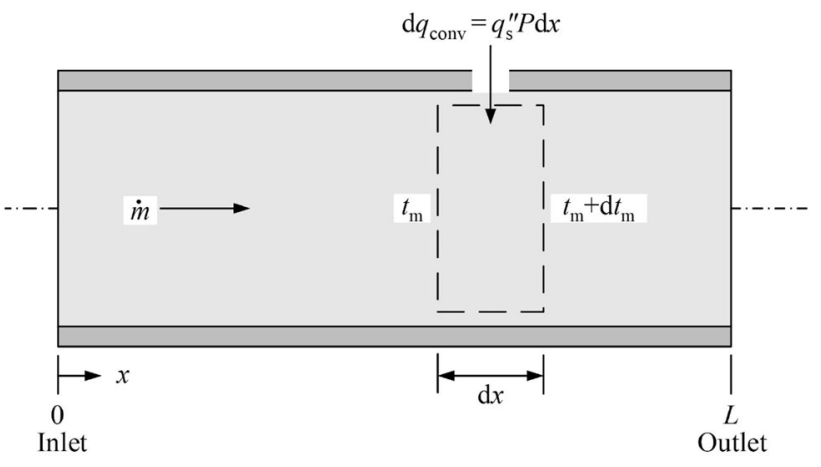

Fig. 11 Control volume for internal flow in a tube

By defining $\Delta t=t_{\mathrm{s}}-t_{\mathrm{m}}$, Eq. (36) may be expressed as $\frac{\mathrm{d} t_{\mathrm{m}}}{\mathrm{d} x}=-\frac{\mathrm{d} \Delta t}{\mathrm{~d} x}=\frac{P}{\dot{m} c_{\mathrm{p}}} h \Delta t$,

where $P$ is the surface perimeter. Separating the variables and integrating from the tube inlet to the outlet,

$\frac{\Delta t_{\mathrm{o}}}{\Delta t_{\mathrm{i}}}=\frac{t_{\mathrm{s}}-t_{\mathrm{m}, \mathrm{o}}}{t_{\mathrm{s}}-t_{\mathrm{m}, \mathrm{i}}}=\exp \left(-\frac{P L}{\dot{m} c_{\mathrm{p}}} \bar{h}\right), \quad t_{\mathrm{s}}=$ constant,

where $\bar{h}$ is the average convection heat transfer coefficient and $L$ is the characteristic length. Eq. (35) can be expressed as the following form

$q_{\mathrm{conv}}=\dot{m} c_{\mathrm{p}}\left(\left(t_{\mathrm{s}}-t_{\mathrm{m}, \mathrm{i}}\right)-\left(t_{\mathrm{s}}-t_{\mathrm{m}, \mathrm{o}}\right)\right)=\dot{m} c_{\mathrm{p}}\left(\Delta t_{\mathrm{i}}-\Delta t_{\mathrm{o}}\right)$.

The rate equation can be obtained as follows by combining Eqs. (38) and (39)

$q_{\mathrm{conv}}=\bar{h} A_{\mathrm{s}} \Delta t_{\mathrm{lm}}, \quad t_{\mathrm{s}}=$ constant,

where $A_{\mathrm{s}}$ is the internal surface area of the coolant tank and $\Delta t_{\mathrm{lm}}$ is the log mean temperature difference

$\Delta t_{\operatorname{lm}} \equiv \frac{\Delta t_{\mathrm{o}}-\Delta t_{\mathrm{i}}}{\ln \left(\Delta t_{\mathrm{o}} / \Delta t_{\mathrm{i}}\right)}$.

Combining the energy balance equation (Eq. (35)) with the rate equation (Eq. (40)), the average convection coefficient is expressed as

$\bar{h}=\frac{\dot{m} c_{\mathrm{p}}}{A_{\mathrm{c}} L} \frac{\left(t_{\mathrm{m}, \mathrm{o}}-t_{\mathrm{m}, \mathrm{i}}\right)}{\Delta t_{\mathrm{lm}}}$.

Figure 12 shows the shift in the curve of the heat transfer coefficient $h_{\mathrm{s}}$ with change in the flow rate of the coolant.

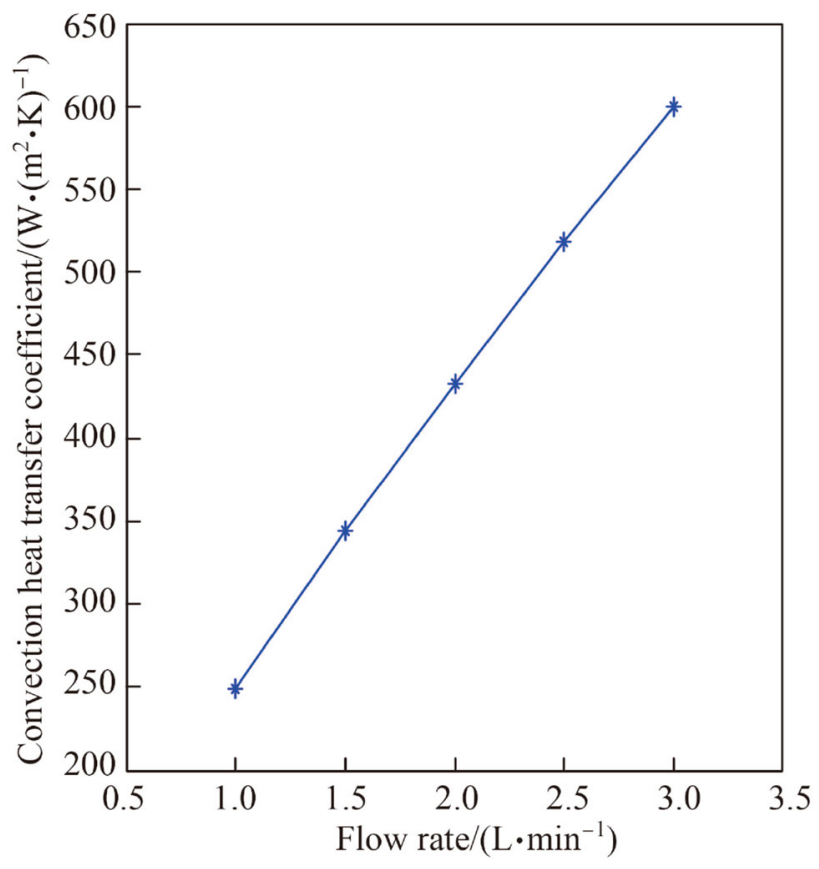

Fig. 12 Heat transfer coefficient $h_{\mathrm{s}}$ versus the flow rate of the coolant

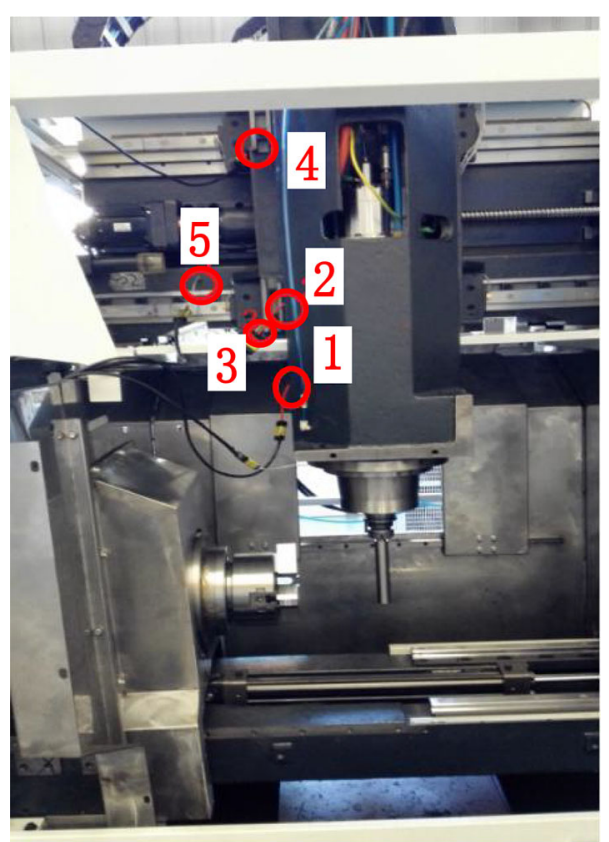

Fig. 13 Overall position of the sensors

\section{Temperature rise experiments for motorized spindle}

In order to verify the accuracy and effectiveness of the calculated results of the temperature variation of each component of the spindle system by the above thermal resistance network model, temperature increase experiments are carried out to detect the temperature of the 

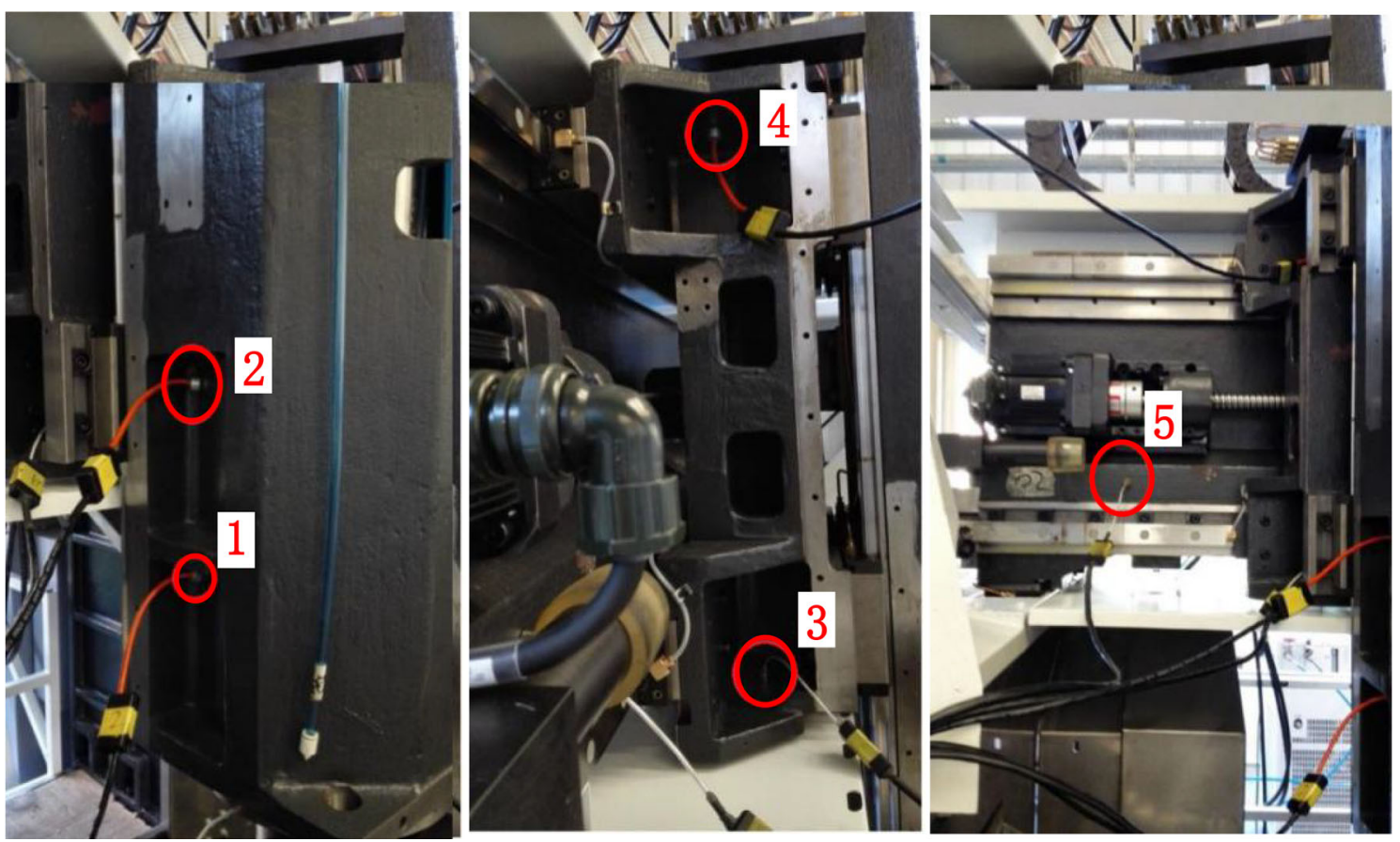

Fig. 14 Specific position of the sensors

Table 4 List of the test positions

\begin{tabular}{lllll}
\hline Position 1 & Position 2 & Position 3 & Position 4 & Position 5 \\
\hline The front bearing & The rear bearing & The lower end-face of headstock & The upper end face of headstock \\
\hline
\end{tabular}

spindle at different speeds. Five-channel magnetic highprecision temperature sensors are used as the test equipment; they have a precision of $\pm 0.1{ }^{\circ} \mathrm{C}$. The ambient temperature is set to be $23{ }^{\circ} \mathrm{C}$.

The overall position of the sensors is shown in Fig. 13; the specific positions of the sensors are presented in Fig. 14 and Table 4. After being attached to the designated position, the high-precision temperature sensors are connected to the data acquisition unit and the laptop through the USB data cable. Then, the test software is opened for the temperature test. Four sets of experiments are carried out at four rotational speeds of $1000 \mathrm{r} / \mathrm{min}, 4000 \mathrm{r} / \mathrm{min}, 6000$ $\mathrm{r} / \mathrm{min}$, and $10000 \mathrm{r} / \mathrm{min}$, with the spindle operating for $4 \mathrm{~h}$ and stopped for $3 \mathrm{~h}$ in each test set. This was done to ensure that the spindle was in a cold state at the beginning of each test.

\section{Results and discussion}

\subsection{Analysis of temperature distribution}

By solving the matrix equation (Eq. (2)), the temperature variation of each thermal node in the thermal resistance network model at a certain rotational speed can be obtained. Simultaneously, the calculated results are verified by comparing with the experimental results of the temperature increase test described in Sect. 4. The comparison results are shown in Fig. 15, wherein Fig. 15a shows the comparison result of the spindle system at $6000 \mathrm{r} / \mathrm{min}$, and Fig. 15b shows the comparison result at $10000 \mathrm{r} / \mathrm{min}$

The experimental results demonstrate that when the rotational speed is $6000 \mathrm{r} / \mathrm{min}$, the temperature rises rapidly in the initial stage of the operating process, attaining the thermal equilibrium state at approximately 1 $300 \mathrm{~s}$. The thermal equilibrium temperatures at the shell of the front and rear bearings are $21.3{ }^{\circ} \mathrm{C}$ and $22.3{ }^{\circ} \mathrm{C}$, respectively; when the rotational speed is $10000 \mathrm{r} / \mathrm{min}$, the temperatures at the shells of the front and rear bearings exhibit a relatively rapid upward trend, achieving thermal equilibrium at approximately $1500 \mathrm{~s}$ and temperatures of 


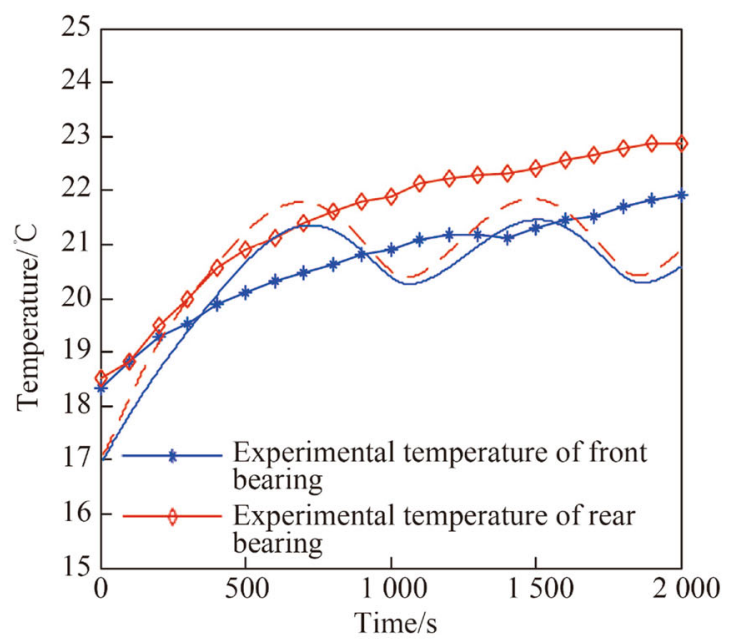

(a) $6000 \mathrm{r} / \mathrm{min}$

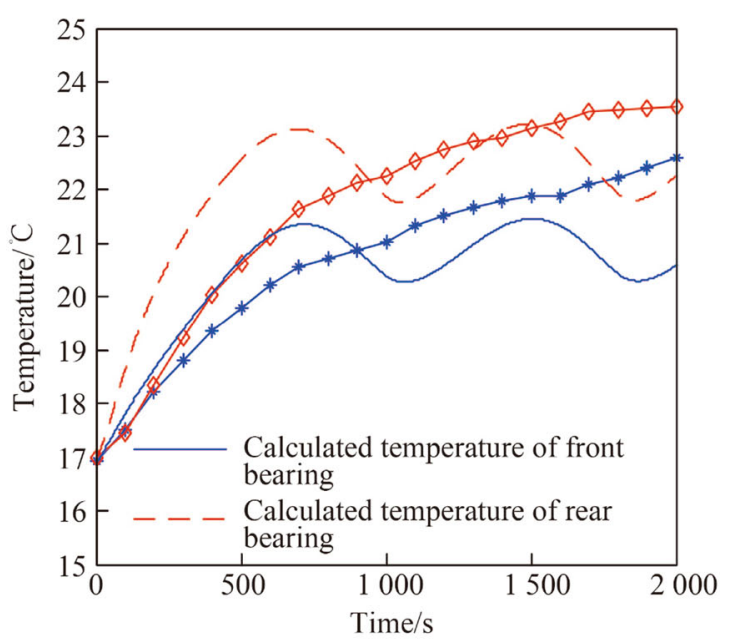

(b) $10000 \mathrm{r} / \mathrm{min}$

Fig. 15 Comparison between the experimental temperature and the calculated temperature

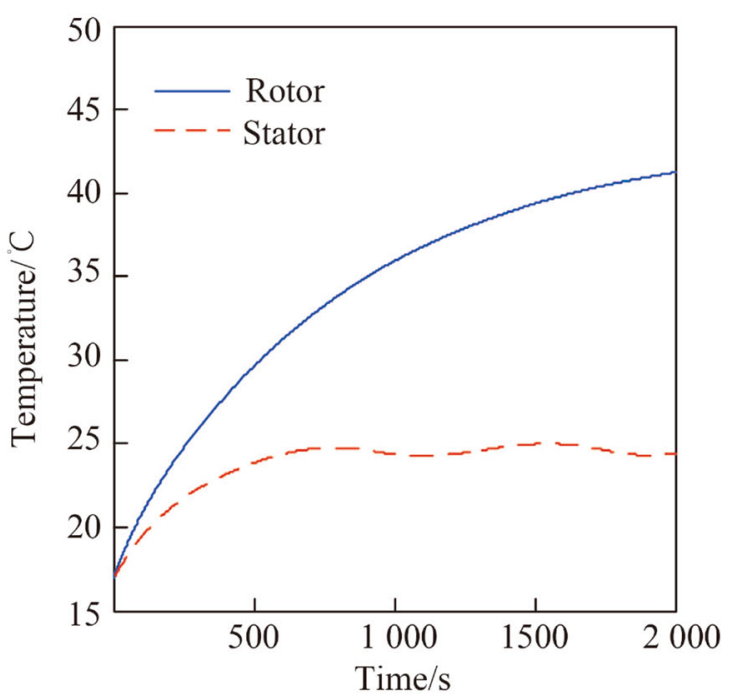

(a) $6000 \mathrm{r} / \mathrm{min}$

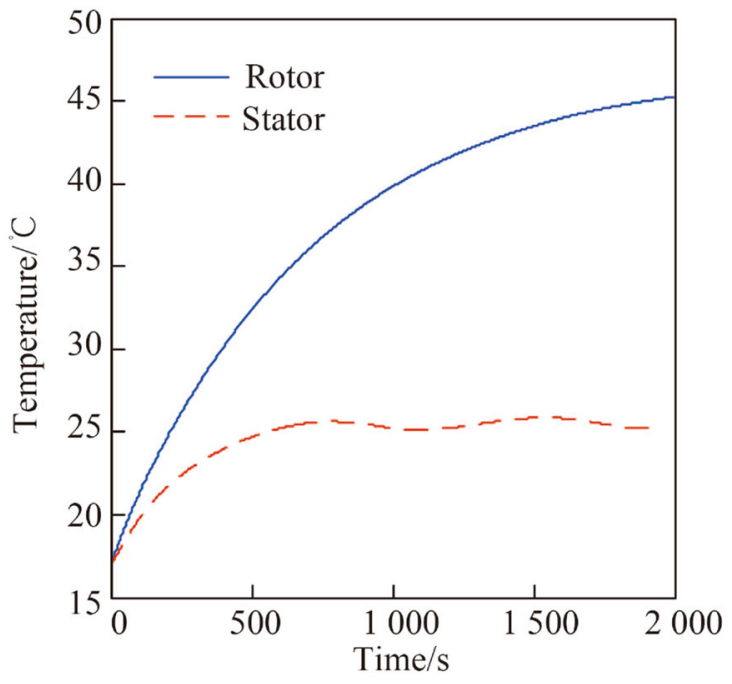

(b) $10000 \mathrm{r} / \mathrm{min}$

Fig. 16 Temperature variation of the rotor and the stator

$21.8^{\circ} \mathrm{C}$ and $23.1^{\circ} \mathrm{C}$, respectively. The results calculated by the thermal resistance network method reveal that the temperatures of the front and rear bearings exhibit a similar trend, with a fluctuation of approximately $1.5^{\circ} \mathrm{C}$. This is owing to the PID control of the heat exchanger in the oilwater heat exchange cooling system of the stator in the actual process. It is set such that the heat exchanger starts to operate when the temperature of the coolant outlet attains $22{ }^{\circ} \mathrm{C}$ and stops when the temperature reduces to 19 ${ }^{\circ} \mathrm{C}$. The thermal equilibrium temperature of each node is defined as the average of its steady fluctuations. Thus, the thermal equilibrium temperatures of the front and rear bearings are $20.8{ }^{\circ} \mathrm{C}$ and $20.5{ }^{\circ} \mathrm{C}$, respectively, at 6000 $\mathrm{r} / \mathrm{min}$. When the speed is $10000 \mathrm{r} / \mathrm{min}$, the thermal equilibrium temperatures of the front and rear bearings are $20.8^{\circ} \mathrm{C}$ and $22.5{ }^{\circ} \mathrm{C}$, respectively.

Figure 16 shows the temperature variation of the rotor and stator in the spindle system. It is evident that both the rotor and stator heat up from an initial temperature of 18 ${ }^{\circ} \mathrm{C}$. The rotor heats up more rapidly during the initial stage, attaining a thermal equilibrium state at approximately 1 $800 \mathrm{~s}$ with equilibrium temperatures of $41.1{ }^{\circ} \mathrm{C}$ and 45.0 ${ }^{\circ} \mathrm{C}$, respectively, at these two operating conditions. Meanwhile, the stator attains equilibrium at approximately $800 \mathrm{~s}$, which is shorter than that for the rotor. The equilibrium temperature at $6000 \mathrm{r} / \mathrm{min}$ and $10000 \mathrm{r} / \mathrm{min}$ are $24.9^{\circ} \mathrm{C}$ and $25.1{ }^{\circ} \mathrm{C}$, respectively. Figure 16 shows that the equilibrium temperature of the stator is higher than that of 


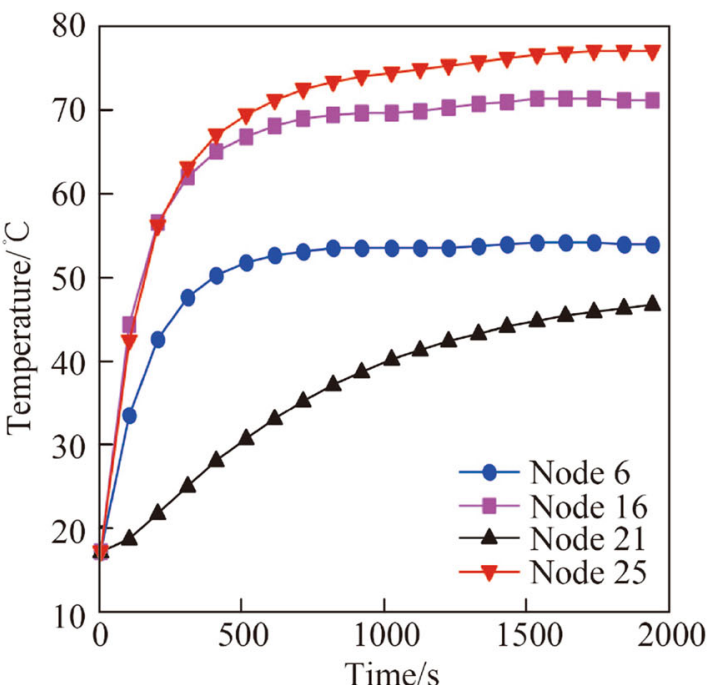

(a) Shaft

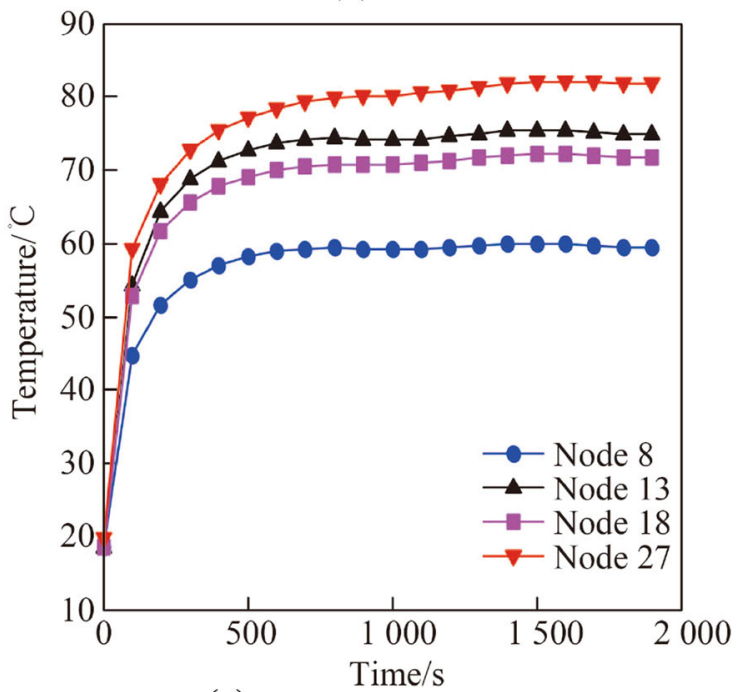

(c) Rollers of the bearings

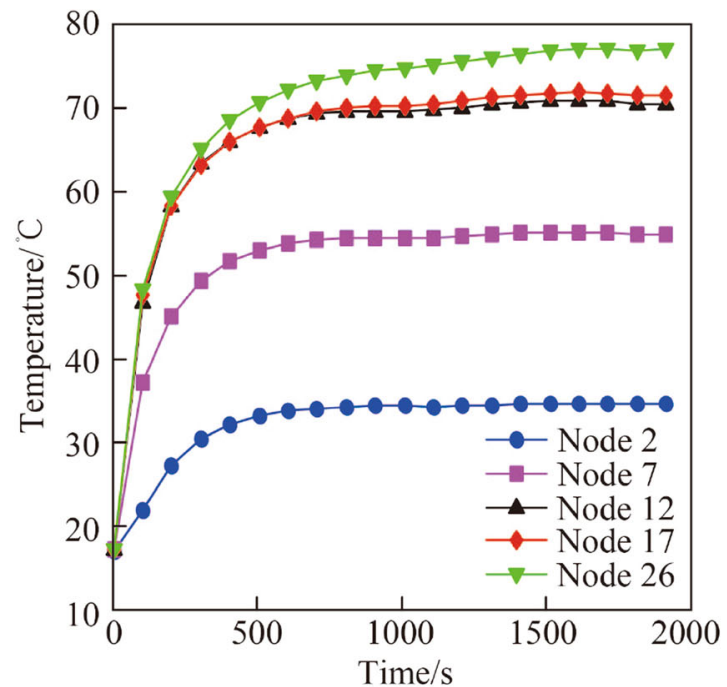

(b) Inner rings of the bearings

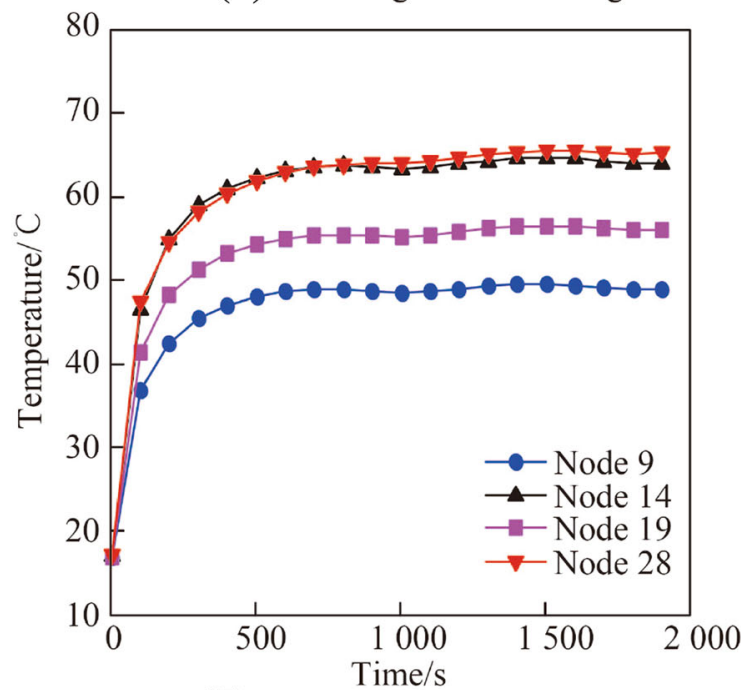

(d) Inner rings of the bearings

Fig. 17 Temperature of other components at the speed of $10000 \mathrm{r} / \mathrm{min}$

the rotor. This is because the stator, which is closer to the cooling water jacket than to the rotor, exhibits a better heat dissipation effect, whereas the rotor is located at the center of the shaft. Figure 17 shows the temperature curves of the other main components of the spindle system at the rotational speed of $10000 \mathrm{r} / \mathrm{min}$, including the thermal nodes on the inner and outer rings of the bearings, the rollers of the bearings, and the shaft. Figures 16 and 17 indicate that the temperature variation of each component exhibits a similar trend; that is, the temperature rise is more rapid at the initial stage, attaining the thermal equilibrium state at approximately $800 \mathrm{~s}$, and the equilibrium temperature fluctuates marginally with the change in the temperature of the coolant.

When the spindle system runs at a certain speed for a period of time, the whole system attains a state of thermal equilibrium; that is, the temperature of each component increases to a stable value. For example, the equilibrium temperatures of the thermal nodes in Fig. 4 when the rotational speed is $10000 \mathrm{r} / \mathrm{min}$ are shown in Table 5 .

\subsection{Analysis of influencing factors}

The structure of the spindle system investigated in this study has been described above. The maximum rotational speed is $12000 \mathrm{r} / \mathrm{min}$, and the rated power is $11 \mathrm{~kW}$. This section mainly discusses the influence of certain main parameters on the thermal characteristics of the spindle system, including the rotational speed and cooling conditions. 
Table 5 Steady-state temperature distribution of the spindle system

\begin{tabular}{|c|c|}
\hline No. & Temperature $/{ }^{\circ} \mathrm{C}$ \\
\hline 1 & 40.5 \\
\hline 2 & 34.7 \\
\hline 3 & 23.4 \\
\hline 4 & 10.1 \\
\hline 5 & 22.3 \\
\hline 6 & 53.3 \\
\hline 7 & 55.3 \\
\hline 8 & 59.7 \\
\hline 9 & 49.2 \\
\hline 10 & 22.4 \\
\hline 11 & 68.7 \\
\hline 12 & 71.1 \\
\hline 13 & 75.1 \\
\hline 14 & 64.3 \\
\hline 15 & 22.4 \\
\hline 16 & 70.4 \\
\hline 17 & 72.2 \\
\hline 18 & 72.0 \\
\hline 19 & 56.3 \\
\hline 20 & 22.4 \\
\hline 21 & 46.4 \\
\hline 22 & 45.2 \\
\hline 23 & 25.4 \\
\hline 24 & 20.7 \\
\hline 25 & 76.1 \\
\hline 26 & 77.6 \\
\hline 27 & 82.1 \\
\hline 28 & 65.5 \\
\hline 29 & 20.8 \\
\hline 30 & 20.7 \\
\hline 31 & 20.7 \\
\hline 32 & 23.0 \\
\hline
\end{tabular}

\subsubsection{Analysis of rotational speed}

As the rotational speed exerts a direct impact on the bearing friction torque, affecting the bearing friction heat generation rate, it is a major factor affecting the thermal characteristics of the spindle system. The transient temperature variation of the components at different speeds under a similar condition is shown in Fig. 18. The curves in Fig. 18 indicate that the higher the speed is, the more rapidly the components heat up, and the higher the steady state temperature is when heat balance is attained. Figure 19 shows the steady-state temperature of each component at different rotational speeds under identical cooling conditions. It is evident that with the increase in the rotational speed, the temperatures of all the components of the spindle system when heat balance is attained undergo certain increase. As the speed increases from $2000 \mathrm{r} / \mathrm{min}$ to $12000 \mathrm{r} / \mathrm{min}$, the temperatures at the outer rings of the front and rear bearings increase by $61.2{ }^{\circ} \mathrm{C}$ and $52.4{ }^{\circ} \mathrm{C}$ respectively, whereas the temperatures at the rotor and stator increase by $7.2{ }^{\circ} \mathrm{C}$ and $1.2{ }^{\circ} \mathrm{C}$, respectively. In addition, from Figs. 18 and 19, it is also evident that the effect of the rotational speed on the temperature of the bearing is more significant than that of the rotor and stator. This is because the rotational speed exerts an important influence on the heat generation rate of the bearing. As the speed increases, the heat generation rate and temperature of the bearing increase significantly.

\subsubsection{Analysis of cooling conditions}

In the thermal model of the motorized spindle system, the cooling conditions and heat generation simultaneously affect the thermal characteristics of the system. Therefore, the influence of the cooling system on the temperature variation of the spindle system cannot be omitted. Figure 20 shows the temperatures at the outer rings of the front and rear bearings under different coolant flow rates at a certain rotational speed. It is evident that the temperature increases with the increase in speed and decreases as the coolant flow rate increases. Considering the temperature for $10000 \mathrm{r} / \mathrm{min}$ as an example, the temperature of front bearing \#2 is $83.7^{\circ} \mathrm{C}$ when the coolant flow rate is $1 \mathrm{~L} / \mathrm{min}$; meanwhile, at the flow rate of $3 \mathrm{~L} / \mathrm{min}$, the temperature is $78.0^{\circ} \mathrm{C}$, which is a relative decrease of $5.7^{\circ} \mathrm{C}$. However, at $2000 \mathrm{r} / \mathrm{min}$, the temperature of the nodes under each flow rate is not significantly different, whereas there is a difference of $3-5^{\circ} \mathrm{C}$ at $12000 \mathrm{r} / \mathrm{min}$. This indicates that the effect of the coolant flow rate on the temperature variation of the bearings is more pronounced at higher rotational speeds.

Figure 21a shows the steady-state temperature of the stator under different coolant flow rates. It is evident that the coolant flow rate exerts a significant effect on the cooling performance of the spindle system. For example, at $12000 \mathrm{r} / \mathrm{min}$ and a coolant flow rate of $3 \mathrm{~L} / \mathrm{min}$, the temperature of the stator is $27.4{ }^{\circ} \mathrm{C}$, which is a decrease of $2.4{ }^{\circ} \mathrm{C}$ compared to the temperature at $1 \mathrm{~L} / \mathrm{min}$. Figure $21 \mathrm{~b}$ shows the steady-state temperature of the stator at different coolant flow rates at the speed of $10000 \mathrm{r} / \mathrm{min}$. It is evident from Fig. 21 that the temperature of the stator decreases with the increase in the coolant flow rate. That is, a better cooling condition can effectively improve the heat dissipation efficiency and suppress the temperature increase of the components. 

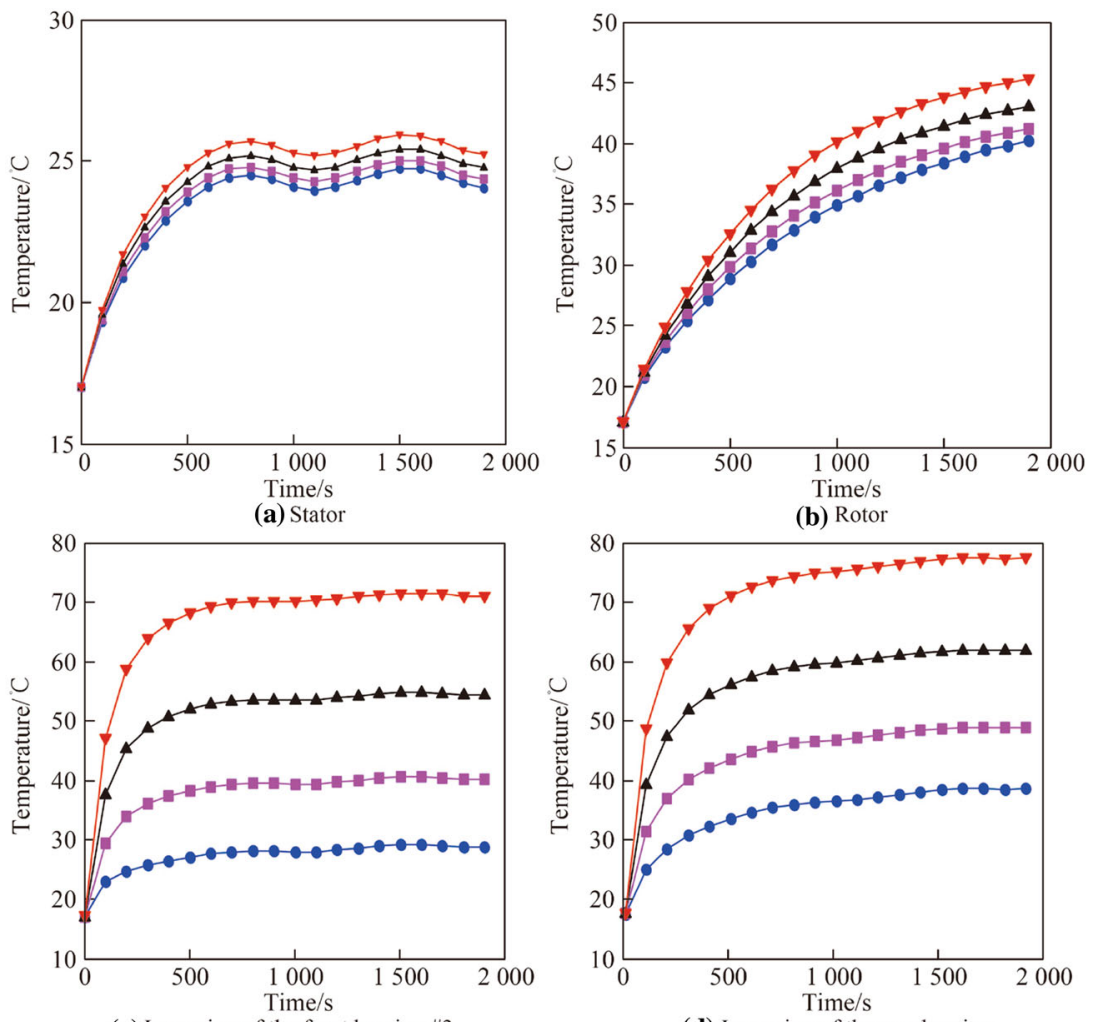

(c) Inner ring of the front bearing \#3

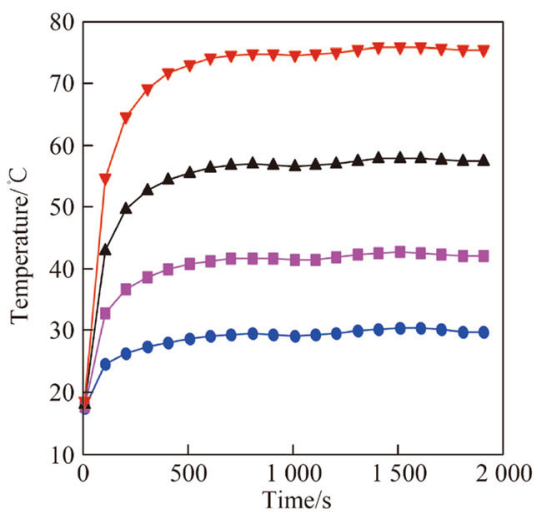

(d) Inner ring of the rear bearing

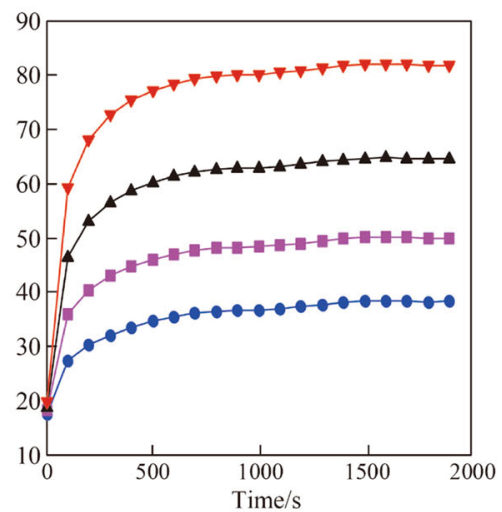

(e) Roller of the front bearing \#3

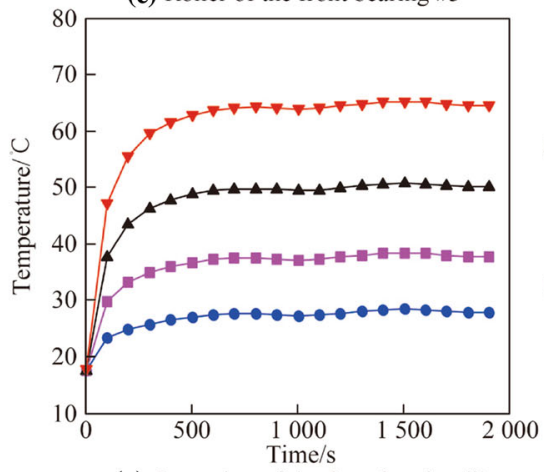

(g) Outer ring of the front bearing \#3

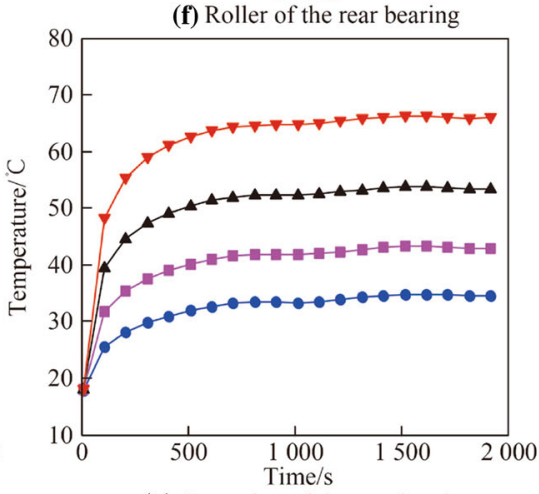

(h) Outer ring of the rear bearing

$$
\longrightarrow 4000 \mathrm{r} / \mathrm{min} \longrightarrow 6000 \mathrm{r} / \mathrm{min} \longrightarrow-6000 \mathrm{r} / \mathrm{min} \longrightarrow 10000 \mathrm{r} / \mathrm{min}
$$

Fig. 18 Transient temperature variation of the components at different speeds 


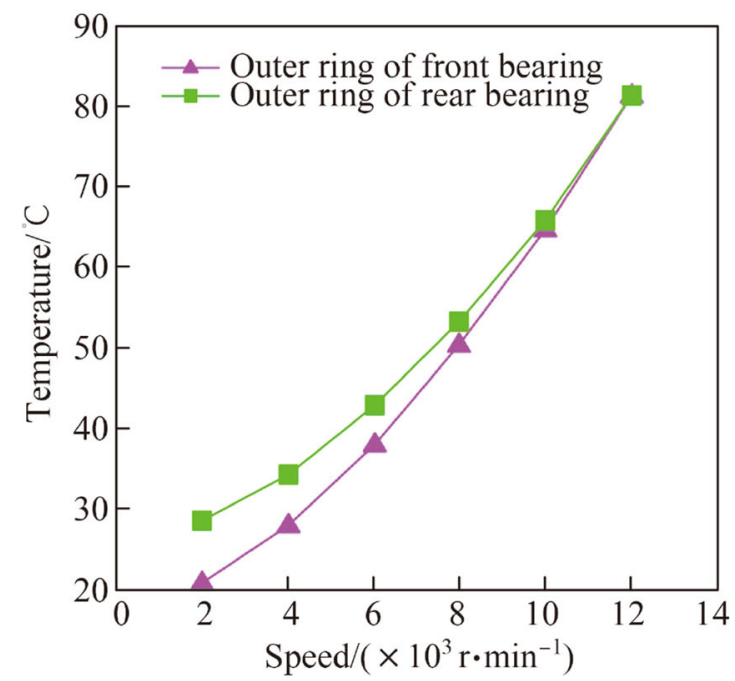

(a) Outer rings of the bearings

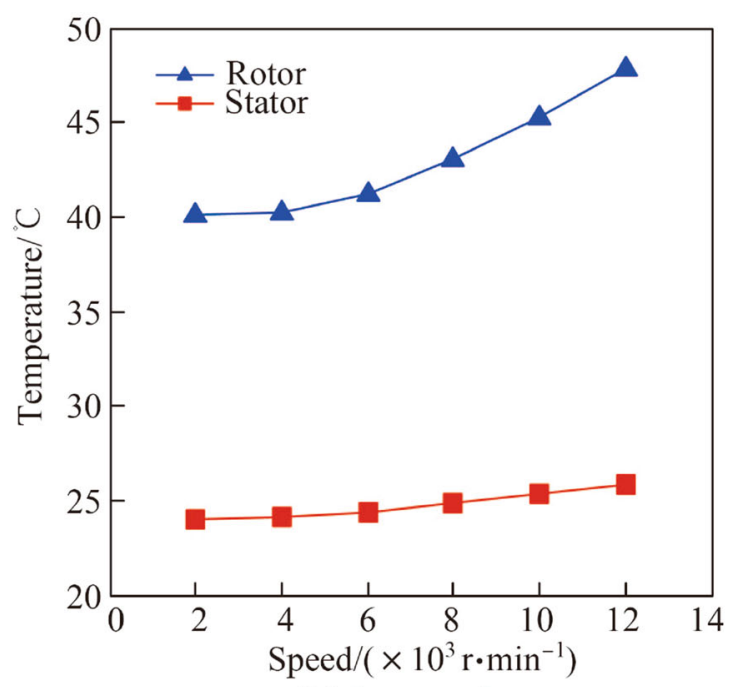

(b) Stator and rotor

Fig. 19 Steady-state temperature of components at different speeds

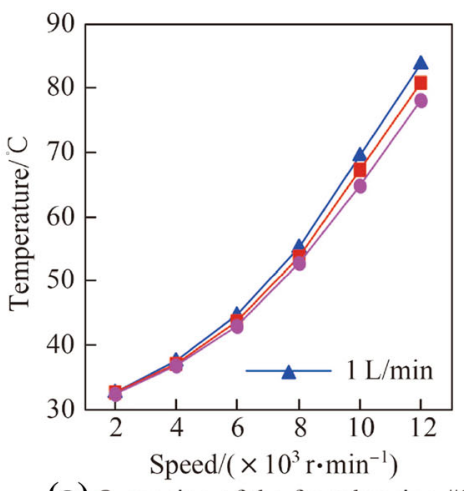

(a) Outer ring of the front bearing \#2

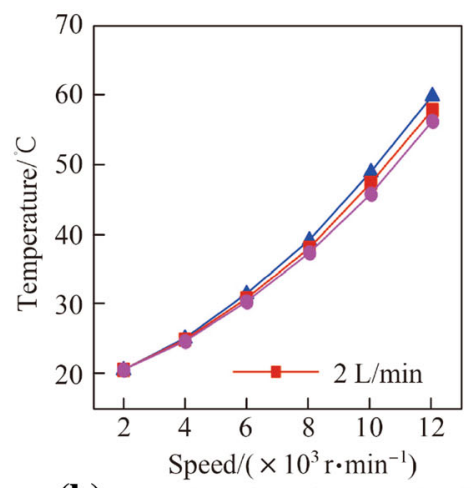

(b) Outer ring of the front bearing \#4

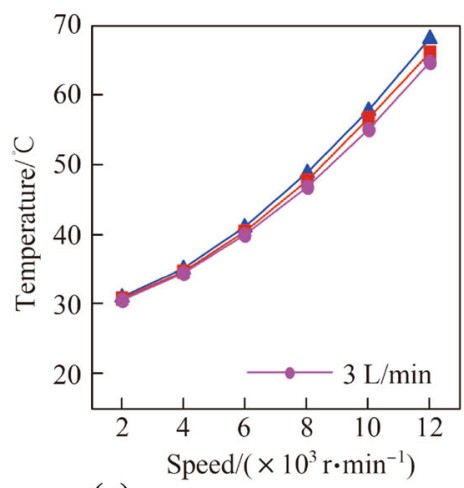

(c) Outer ring of the rear bearing

Fig. 20 Steady-state temperature of components at different flow rates

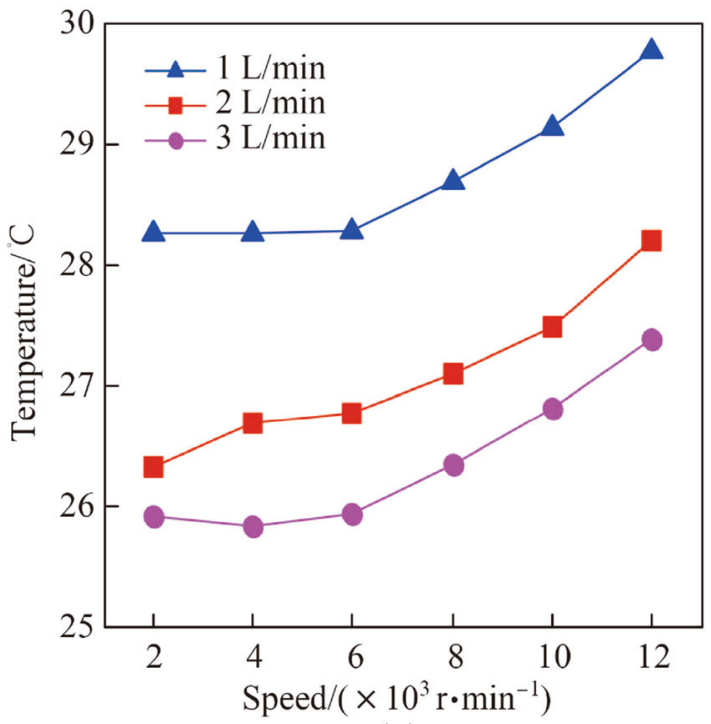

(a)

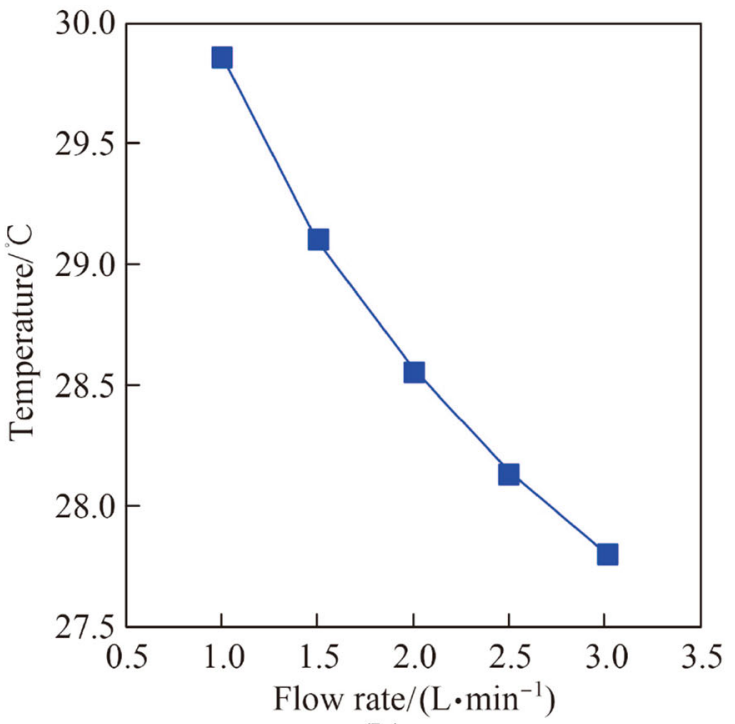

(b)

Fig. 21 Temperature of the stator at different conditions 


\section{Conclusions}

In this study, the thermal resistance network model of the motorized spindle system of a CNC machining center is established to characterize the temperature field distribution of the spindle system. Unlike traditional models, this improved model not only considers the thermal-conduction resistance, thermal-contact resistance, and thermal-convection resistance but also introduces the fitted curve of the temperature variation of the cooling system. In order to verify the accuracy of the model, the temperature increase experiments of the spindle system are conducted at different speeds. A comparison of the calculated results of the thermal resistance network model with the results of the temperature rise experiment reveals that the model proposed in this paper predicts the temperature variation of the main components of the spindle system with certain accuracy; this lays the foundation for the analysis of the thermal performance of the system. Moreover, by applying this improved model, the temperature distribution of the motorized spindle system during the actual operating process can be more accurately predicted; this exerts certain positive influence on the improvement of the machining accuracy of CNC machine tool.

Acknowledgements This work was financially supported by the National Natural Science Foundation of China (Grant No. 51875093), the Fundamental Research Funds for the Central Universities from Ministry of Education of China (Grant Nos. N140304005 and N160313003) and the National Science Foundation for Postdoctoral Scientists of China (Grant Nos. 2014M551105 and 2015T80269).

Open Access This article is distributed under the terms of the Creative Commons Attribution 4.0 International License (http://crea tivecommons.org/licenses/by/4.0/), which permits unrestricted use, distribution, and reproduction in any medium, provided you give appropriate credit to the original author(s) and the source, provide a link to the Creative Commons license, and indicate if changes were made.

\section{References}

1. Zhao HT, Yang JG, Shen JH (2007) Simulation of thermal behavior of a CNC machine tool spindle. Int J Mach Tools Manuf 47(6): 1003-1010

2. Zhu Z, Hu PH, Tao Y et al (2008) 3D analysis of temperature field and thermal deformation of spindle axis. Tool Eng 42(4):66-68

3. Yang H, Ni S (2003) Dynamic modeling for machine tool thermal error compensation. J Manuf Sci Eng 125(2):245-254

4. Jiang S, Zhao ZG, Sun ML et al (2013) Analysis on thermal dynamic characteristics of CNC machine tool spindle. J Tianjin Univ 46(9):846-850

5. Xie LM, Li XQ, Yang J (2007) The research of spindle components' thermal character in NC machines. Modul Mach Tool Autom Manuf Tech 12:21-22
6. Kang Y, Chang CW, Huang Y et al (2007) Modification of a neural network utilizing hybrid filters for the compensation of thermal deformation in machine tools. Int $\mathrm{J}$ Mach Tools Manuf 47(2):376-387

7. Mian N, Fletcher S, Longstaff AP et al (2008) Novel and efficient thermal error reduction strategy for machine tool performance improvement. Univ Hudders 215(4):1219-1228

8. Holkup T, Cao H, Koláŕ P et al (2010) Thermo-mechanical model of spindles. CIRP Ann Manuf Technol 59(1):365-368

9. Zhang J, Li H (2012) Thermal performance analysis for the machine tool's spindle. In: IEEE conference on industrial electronics and applications, pp 2131-2134

10. Xiang S, Zhu X, Yang J (2014) Modeling for spindle thermal error in machine tools based on mechanism analysis and thermal basic characteristics tests. Proc Inst Mech Eng Part C J Mech Eng Sci 228(18):3381-3394

11. Than VT, Huang JH (2016) Nonlinear thermal effects on highspeed spindle bearings subjected to preload. Tribol Int 96:361-372

12. Bossmanns B, Tu JF (1999) A thermal model for high speed motorized spindles. Int J Mach Tools Manuf 39(9):1345-1366

13. Bossmanns B, Tu JF (2001) A power flow model for high speed motorized spindles-heat generation characterization. J Manuf Sci Eng. https://doi.org/10.1115/1.1349555

14. Zverev IA, Eun IU, Chung WJ et al (2003) Thermal model of high-speed spindle units. KSME Int J 2(5):306-315

15. Huang DY, Hong J, Zhang JH et al (2012) Thermal resistance network for solving temperature field in spindle system. J Xi'an Jiaotong Univ 46(5):63-66

16. Liu CH, Luo GJ, He W et al (2010) Steady state thermal analysis of a spindle system based on thermal network. China Mech Eng 6:631-635

17. Liu Z, Pan M, Zhang A et al (2015) Thermal characteristic analysis of high-speed motorized spindle system based on thermal contact resistance and thermal-conduction resistance. Int $\mathrm{J}$ Adv Manuf Technol 76(9-12):1913-1926

18. Wu L, Tan Q (2016) Thermal characteristic analysis and experimental study of a spindle-bearing system. Entropy. https://doi. org/10.3390/e18070271

19. Xu M, Jiang S, Cai Y (2007) An improved thermal model for machine tool bearings. Int J Mach Tools Manuf 47(1):53-62

20. Ma C, Yang J, Zhao L et al (2015) Simulation and experimental study on the thermally induced deformations of high-speed spindle system. Appl Therm Eng 86:251-268

21. Ma C, Zhao L, Shi H et al (2015) Experimental and simulation study on the thermal characteristics of the high-speed spindle system. Proc Inst Mech Eng Part C J Mech Eng Sci 231(6):1072-1093

22. Yu WD (2014) Thermal deformation analysis and structural optimization of motorized spindle. Dissertation, Shenyang Jianzhu University

23. Jiang SY, Mao HB (2010) Investigation of variable optimum preload for a machine tool spindle. Int $\mathrm{J}$ Mach Tools Manuf 50:19-28

24. Palmgren A (1946) Ball and roller bearing engineering. Industries, Burbank

25. Wan CS (1987) Analysis of rolling bearings. China Machine Press, Beijing

26. Yang SM, Tao WQ (2006) Heat transfer. Higher Education Press, Beijing

27. Bianchi Ana-Maria (2008) Heat transfer. Dalian University of Technology Press, Dalian

28. Incropera FP, DeWitt DP et al (1981) Fundamentals of heat and mass transfer. Wiley, New York 